Linköping University Medical Dissertation No.1687

\title{
The Importance of Macrophages, Lipid Membranes and Seeding in Experimental AA Amyloidosis
}

Aida Vahdat Shariat Panahi
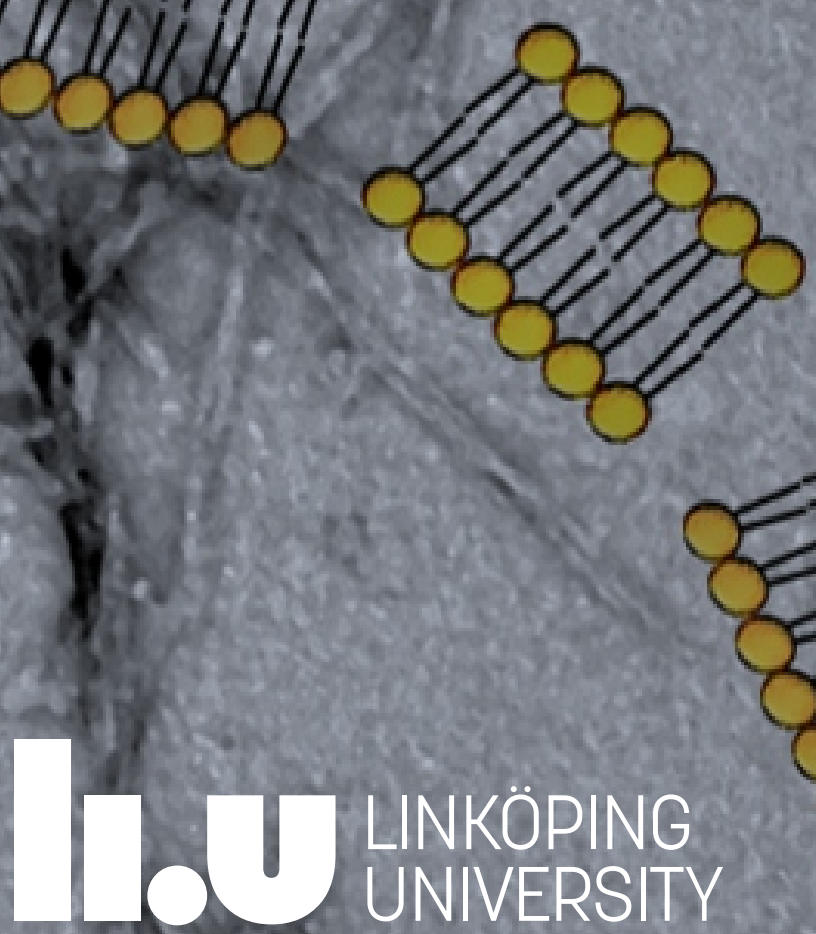


\title{
The Importance of Macrophages, Lipid Membranes and Seeding in Experimental AA Amyloidosis
}

\author{
Aida Vahdat Shariat Panahi
}

Experimental Pathology

Department of Clinical and Experimental Medicine

Faculty of Medicine and Health Sciences

Linköping University, SE-581 83 Linköping, Sweden

Linköping 2019 
Copyright (C) Aida Vahdat Shariat Panahi, 2019

The Importance of Macrophages, Lipid Membranes and Seeding in Experimental AA Amyloidosis.

ISBN: 978-91-7685-050-3

ISSN: 0345-0082

Printed in Sweden by LiU-Tryck, Linköping, 2019 
To My Family 



\section{Abstract}

Amyloidosis is a group of protein misfolding diseases caused by tissue deposition of fibrillary protein aggregates termed amyloid. Amyloid A (AA) amyloidosis is a systemic form of amyloidosis that occurs as a complication of chronic inflammatory diseases, such as rheumatoid arthritis, familial Mediterranean fever and chronic infections, such as tuberculosis. AA amyloid is derived from the precursor protein serum amyloid A and is deposited in several organs preferably kidneys, liver and spleen. AA amyloidosis can be induced in mice by long standing inflammatory stimulation and concurrent administration of tissue extracts of AA amyloid, referred to as amyloid enhancing factor (AEF), reduces the time for amyloid deposition in the marginal zone of the spleen from 5 weeks to 2 days. The general aim of this thesis was to investigate the mechanisms involved in the development of AA amyloid in the mouse model of AA amyloidosis.

Amyloid was induced in inflamed mice by injection of AEF and amyloid toxicity to splenic macrophages was investigated. We found that the marginal zone macrophages were very sensitive to amyloid formation and increasing amyloid load caused progressive depletion of these cells, whereas red pulp macrophages and metallophilic marginal zone macrophages appeared unaffected. To clarify the role of splenic macrophages in amyloidogenesis, macrophages were depleted by clodronate containing liposomes. We displayed that in the absence of splenic macrophages, especially marginal zone macrophages, amyloid formation was delayed implying a crucial role of macrophages in amyloid formation.

The effect of lipid membranes on amyloid formation was studied and we showed that liposomes exhibited an amyloidogenic effect in inflamed mice although not as powerful as AEF. Following the fate of the liposomes, we showed that liposomes were rapidly cleared by uptake in the spleen and liver and colocalized with lysosomes. A tentative mechanism might be that accumulation of liposomes in lysosomes interfere with the SAA degradation process facilitating amyloid formation.

Finally the conformational properties of two AEF (AEF1 and AEF2) preparations were studied using conformation sensitive luminescent-conjugated oligothiophenes (LCOs). We found that AEF1 and AEF2 displayed significantly different ultrastructure as well as conformation and consequently induced different cytotoxicity in vitro. Inducing amyloid formation in inflamed mice by AEF1 and AEF2 revealed that the polymorph of the amyloid aggregates was replicated in vivo.

In summary, the results obtained in this thesis indicate an important role for macrophages for the formation of amyloid. The existence of amyloid strains has long been an in vitro finding, but the finding that AEF ultrastructure drives the morphology of newly formed amyloid in vivo opens up for new studies that can help us to understand the formation of homologous and heterologous fibrils. Thus, the fundamental mechanisms of various amyloid diseases are similar and the results presented in the thesis can increase the understanding of other amyloid diseases. 


\section{Populärvetenskaplig sammanfattning}

Proteiner är viktiga makromolekyler i allt levande och har avgörande betydelse både för cellens struktur och funktion. Proteiner består av lång kedjor av aminosyror som måste veckas till en korrekt tredimensionell struktur för att proteinet ska bli funktionellt. Felaktig veckning av proteiner kan leda till allvarliga sjukdomar eftersom proteiner som inte bryts ner kan klumpa ihop sig, bli olösliga och ansamlas i vävnaden. Ansamling av dessa olösliga proteinaggregat, så kallad amyloid, är associerat med flera sjukdomar och hittills har 36 olika proteiner identifierats som orsakar sjukdomar hos människan. AA-amyloidos är en systemisk form av amyloidos som förekommer över hela världen. Den orsakas av ansamling av akutfasproteinet serumamyloid A (SAA) som utsöndras till blodet vid inflammation. Vid kroniska inflammatoriska tillstånd såsom reumatoid artrit, familjär medelhavsfeber och tuberkulos ökar nivån av SAA i blodet upp till 1000 gånger och hos vissa individer kan det leda till felveckning av proteinet och ackumulering i olika organ, främst njurar, mjälte och lever. När AA-amyloid ansamlas i njurarna leder det till proteinuria.

Musmodeller för AA-amyloidos kan skapas genom långvarig inflammatorisk stimulering och insjuknandet kan påskyndas genom att administrera extrakt som renats fram från vävnad med amyloid, så kallad amyloidförstärkningsfaktor (AEF). I studierna som ligger till grund för avhandlingen har en musmodell använts för att undersöka betydelsen av mjältmakrofager för utvecklingen av AA-amyloidos. Makrofager är vita blodkroppar som kan ta upp och oskadliggöra cellulärt material och främmande ämnen. Vi visar att en specifik typ av makrofager sk marginalzons-makrofager är mycket känsliga för amyloid och minskar i antal när mängden av inlagrad amyloid ökar. Om makrofagerna avlägsnas med hjälp av fettbubblor, så kallade liposomer, innehållande klodronat före amyloidinduktion fördröjs utvecklingen av AA-amyloidos. Vi fann också att injicering av fettmembran i form av liposomer påskyndar amyloidutveckling i inflammerade möss även om den amyloidogena effekten av liposomer var svagare jämfört med AEF. Slutligen karaktäriserar vi två AEF-preparationer med hjälp av fluorescenta prober, luminescerande-konjugerade oligotiofener, för att undersöka om amyloidstrukturerna skiljer sig åt. Vi fann att de två AEF-preparationerna har olika ultrastruktur såväl som olika konformation vilket orsakar olika cytotoxicitet när de inkuberas med cellkulturer in vitro. De två AEF-preparationerna används också för att inducera amyloidbildning i inflammerade möss och vi visar att konformationen av amyloidaggregat replikeras in vivo.

Avhandlingen visar att mjältmakrofager är viktiga för AA-amyloidbildning och att olika population av makrofager är olika känsliga för amyloid. Även om det finns skillnader mellan olika amyloidsjukdomar, visar experimenten med två AEF-preparationer att grundläggande mekanismer ändå är liknande och resultat från studierna av AAamyloidos kan öka förståelsen för andra amyloidsjukdomar. 


\section{Popular summary}

Proteins are important macromolecules in all living organisms, crucial for both structure and function of the cell. Functional proteins consist of amino acids in long chains that are folded into a three-dimensional structure. Misfolding of proteins is a serious condition, since, if not degraded, the protein might start to accumulate in the tissue, leading to a protein misfolding diseases. Amyloidosis is the largest group among the protein misfolding diseases, and hitherto 36 different proteins have been identified as amyloid-forming in human.

AA amyloidosis is a systemic form of amyloidosis with a worldwide distribution. It is caused by the deposition of acute phase protein serum amyloid A (SAA) found in the blood. During inflammation the SAA levels in the circulation can increase 1000-fold within 24 hours and this increase is a prerequisite for amyloid formation. Protein AA amyloid deposits accumulate throughout the body but the main clinical symptom, proteinuria, is caused by AA amyloid deposited in the kidneys.

Mouse models of AA amyloidosis can be generated by prolonged inflammatory stimulation and the disease is accelerated by administration of amyloid extracts, called amyloid enhancing factor (AEF). In the studies that form the basis of the thesis, the mouse model of AA amyloidosis has been used to investigate the importance of splenic macrophages for the development of AA amyloidosis. Macrophages are white blood cells with the ability to engulf cellular debris and foreign substances. We showed that a specific type of macrophages called marginal zone macrophages are very sensitive to amyloid and increasing amyloid load resulted in a progressive depletion of these macrophages. If the macrophages are depleted with lipid vesicles, called liposomes, containing clodronate before amyloid induction, development of AA amyloidosis is delayed. We also found that injecting lipid vesicles in the form of liposomes results in accelerated amyloid formation in inflamed mice, but the amyloidogenic effect of liposomes was weaker compared to AEF. Finally, we characterized two AEF preparations using fluorescent conformation sensitive luminescent-conjugated oligothiophenes. We found that the two AEF preparations displayed various ultrastructure and conformation, which resulted in different cytotoxicity when incubated with cell cultures in vitro. These two AEF preparations were also used to induce amyloid formation in inflamed mice and we observed that the conformation of amyloid aggregates is replicated in vivo.

The results obtained through this $\mathrm{PhD}$ work points to the importance of splenic macrophages for the formation of AA amyloid and that different macrophage populations exhibit different sensitivity to amyloid. Although there are differences between amyloid diseases, the experiments with two AEF preparations show that the fundamental mechanisms are similar and results derived from my studies on AA amyloidosis can increase our understanding of other amyloid diseases. 


\section{Acknowledgements}

There are many people that I would like to thank which have contributed in many different ways to the work behind this thesis:

First of all my supervisor, Prof. Karin Öllinger for her support, patient guidance, encouragement and advice during the time of my research. I have been extremely lucky to have a supervisor who cared so much about my work, and who responded to my questions so promptly. Her positive outlook and confidence in my research inspired me and gave me confidence. Her careful editing contributed enormously to the production of this thesis.

My co-suprevisors Dr. Katarzyna Lundmark and Prof. Gunilla Westermark for teaching me a lot about amyloid and their support, help and guidance during my $\mathrm{PhD}$ study. I benefited greatly from their helpful discussions.

Jakob Domert, Chris Sackmann, Linea Sandin and Kyriakos Orfanidis, my roommates, for making our office such a nice place.

Linda Vainikka, Ida Eriksson and Petra Wäster for all the excellent practical support, help in keeping the lab in order and for all laughs and nice comments during the coffee break.

I also wish to acknowledge the present and former members at the Department of experimental pathology: B-A Fredriksson, Uno Johansson, Karin Roberg, Martin Hallbeck, Emelie Severinsson, Juan Reyes, Katarina Kågedal, Jonas Broman, Max Larsson, Anna Ansell, Valerie Sackmann, Emilia Wiechec, Maria Ntzouni, and Hanna Appelqvist. Thanks for all nice coffee breaks.

Vesa Loitto, for all help with the microscopy.

All my co-authors in the papers.

Per Hammarström for collaboration in the LCOs project and increasing my knowledge on LCOs and amyloid polymorphism. 
Sofie Nyström for collaboration in the LCOs project and teaching me a lot about the LCO staining and the hyperspectral microscopy.

Most importantly, none of this would have been possible without the love, patience and support of my family. I would like to express my deepest gratitude to my mother, Nasrin and my beloved father Mohammad Hadi, who have always loved me unconditionally and whose good examples have taught me to work hard for the things that I aspire to achieve and my brother Ali for his constant encouragement. Additionally, I'd like to thank my mother and father- in- law, Farah and Majid, for their support and their role in encouraging me to finish this work.

Edris, my husband, my love and my best friend, who has been a constant source of support and encouragement. I love you for everything, for being so understanding and believing in me. I thank God for enlightening my life with your presence. Sweet heart I love you! You are the best thing that has ever happened to me.

Finally, I would like to dedicate this work to my 4-year-old son, Ryan, who was, of course, the reason I postponed this dissertation for one year, but his presence inspired me with love and made me stronger, better and more fulfilled than I could have ever imagined. 


\section{Appended papers}

The following papers are appended and will be referred to by their Roman numerals.

[I] Katarzyna Lundmark, Aida Vahdat Shariat Panahi, Gunilla T. Westermark. Depletion of Spleen Macrophages Delays AA Amyloid Development: A Study Performed in the Rapid Mouse Model of AA Amyloidosis. PLoS One. 2013; 8(11): e79104.

[II] Aida Vahdat Shariat Panahi, Per Hultman, Karin Öllinger, Gunilla T Westermark, Katarzyna Lundmark. Lipid membranes accelerate amyloid formation in the mouse model of AA amyloidosis, Amyloid. 2019; 26(1):34-44.

[III] Sofie Nyström*, Aida Vahdat Shariat Panahi*, K Peter R Nilsson, Karin Öllinger, Per Westermark, Gunilla T Westermark, Per Hammarström, Katarzyna Lundmark. Strain-like propagation and cell toxicity of murine AA amyloid polymorphs. Manuscript.

*These authors contributed equally to the work.

Paper I: Open access article published under the terms of the creative common attribution license (CC BY).

Paper II: Reprinted with permission. Originally published by Taylor \& Francis in Journal of Amyloid on March 2019, available online: https://www.tandfonline.com/doi/full/10.1080/13506129.2019.1576606

\section{Publications outside the thesis}

Sofie Nyström, Aida Vahdat Shariat Panahi, K Peter R Nilsson, Per Westermark, Gunilla T Westermark, Per Hammarström, Katarzyna Lundmark. Seed-dependent templating of murine AA amyloidosis. Amyloid. 2017; 24 (sup1):140-141. 


\section{Abbreviations}

AA

APP

AEF

$\mathbf{A} \boldsymbol{\beta}$

CL

CRP

HDL

hFTAA

IAPP

IL

LCO

LDH

Lipo

MARCO

MMZM

MZM

PALS

PEG

PrPc

PrPsc

qFTAA

RPM

SAA

TEM

TNF
Amyloid A

Acute phase protein

Amyloid enhancing factor

Amyloid $\beta$

Liposomes encapsulated clodronate

C-reactive protein

High-density lipoprotein

Heptameric formic thiophene acetic acid

Islet amyloid polypepetide

Interleukin

Luminescent conjugated oligothiophene

Lactate dehydrogenase

Multilayered liposomes containing PBS

Macrophage receptor with collagenous structure

Metallophilic marginal zone macrophage

Marginal zone macrophage

Periarterial lymphatic sheath

Polyethylene glycol

Prion protein

Prion protein scrapi form

Tetrameric formic thiophene acetic acid

Red pulp macrophage

Serum amyloid A

Transmission electron microscopy

Tumor necrosis factor 


\section{Contents}

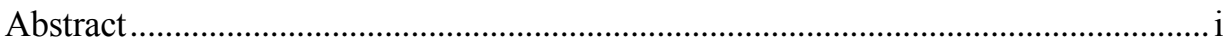

Populärvetenskaplig sammanfattning ..................................................................ii

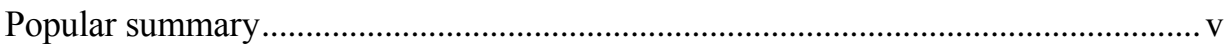

Acknowledgements .......................................................................................... vii

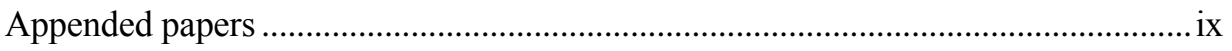

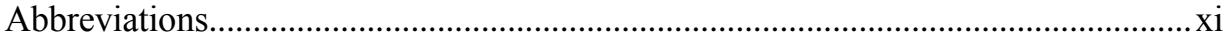

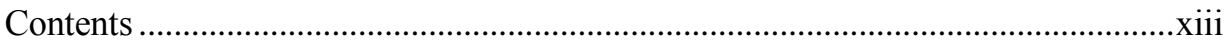

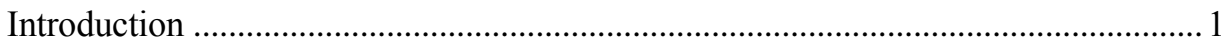

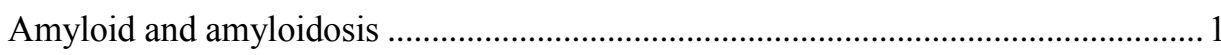

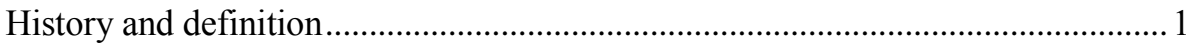

Amyloid fibril structure ..................................................................................... 3

Protein folding and aggregation......................................................................... 4

The free energy landscape of protein folding and aggregation .......................... 5

Pathways of aggregation................................................................................. 6

Seeding and cross seeding ......................................................................... 7

Lipid membrane and amyloid formation .......................................................... 9

Amyloid fibril polymorphism ....................................................................... 10

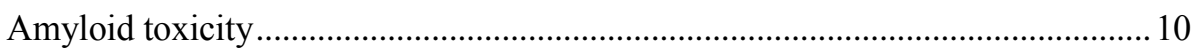

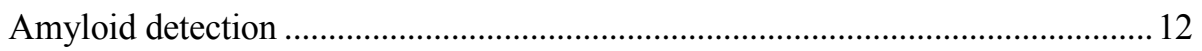

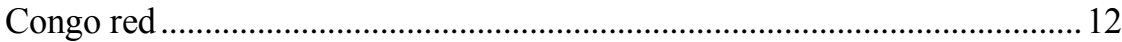

Luminescent conjugated oligothiophenes ..................................................... 12

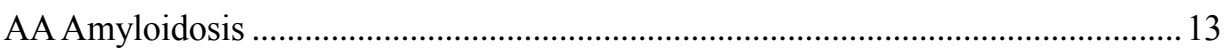

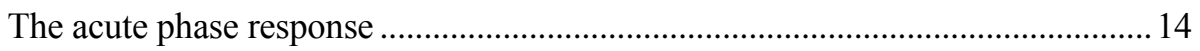

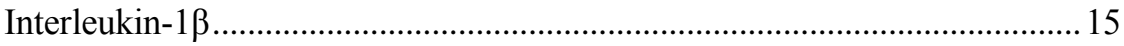

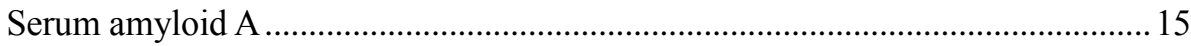

Diagnosis and treatment of AA amyloidosis ........................................................ 17

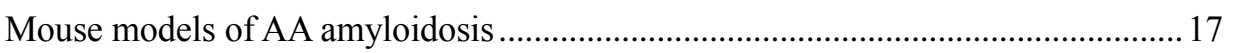

Substances with amyloid enhancing properties...................................................... 18

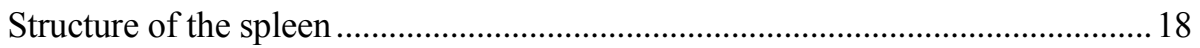

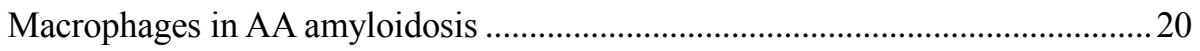


Amyloid clearance

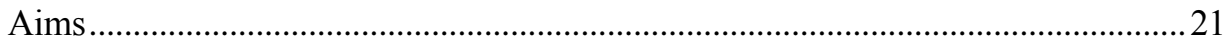

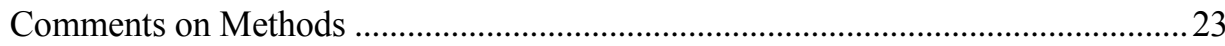

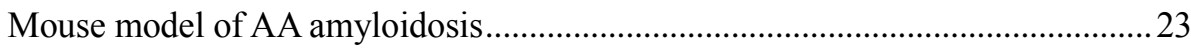

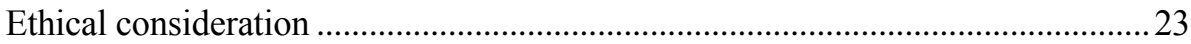

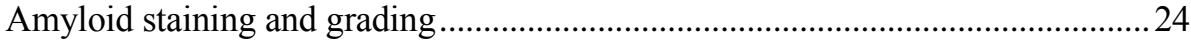

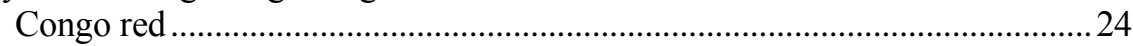

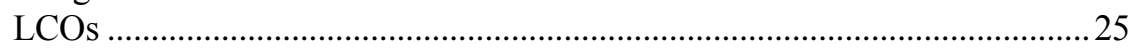

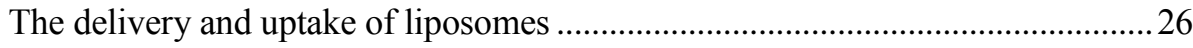

Depletion of macrophages by liposomes encapsulated clodronate.......................26

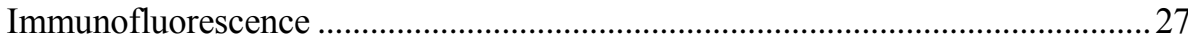

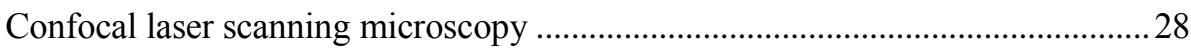

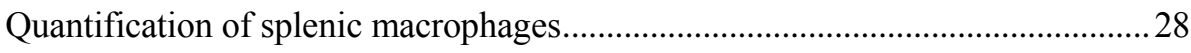

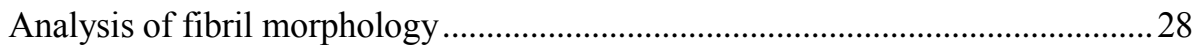

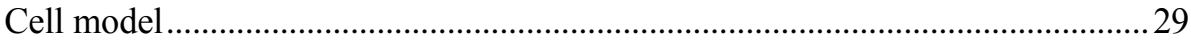

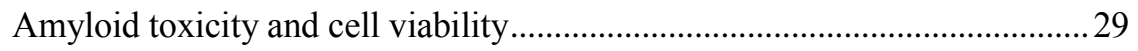

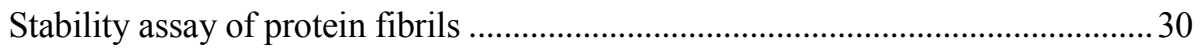

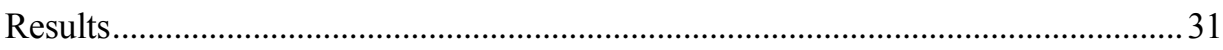

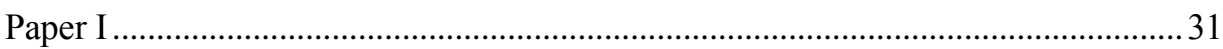

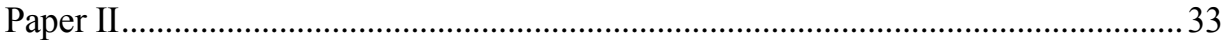

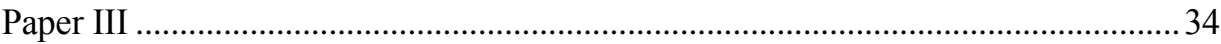

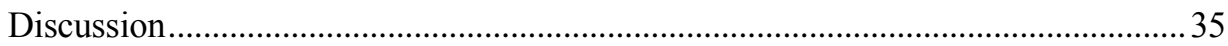

The relevance of mouse models in studies of AA amyloidosis..............................35

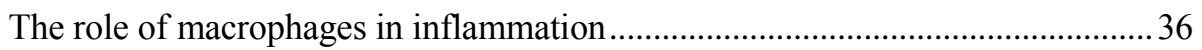

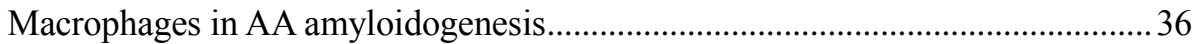

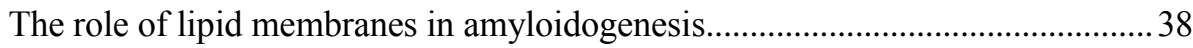

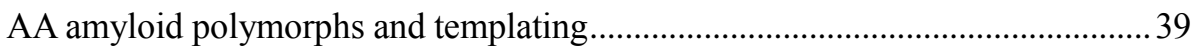

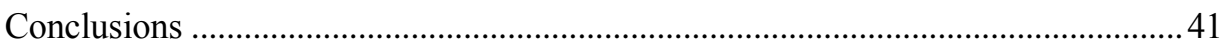

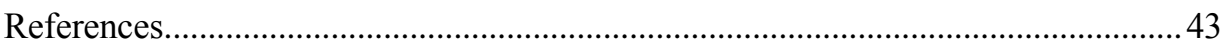




\section{Introduction}

Proteins are highly complex biomolecules that are synthesized on ribosomes as linear amino acid chains and fold into a predetermined three-dimensional structure to obtain functional activity $[1,2]$. Failure to fold properly and remain in the native state occur as a consequence of factors such as; overexpression, mutations, environmental changes and aging. Accumulation of misfolded proteins in various organs can lead to amyloidosis, which constitutes a large group of protein misfolding diseases [3, 4]. Amyloid A (AA) amyloidosis is one of the most common forms of systemic amyloidosis worldwide. It occurs as a complication of chronic inflammatory disorders and chronic infections, which cause overproduction of the acute phase protein serum amyloid A (SAA) resulting in aggregation of amyloid deposits by a mechanism not yet fully elucidated $[5,6]$. Therefore, to understand the mechanism of this disease it is imperative to consider both the role of amyloid formation and inflammation in the process. In this thesis, we used a mouse model of AA amyloidosis to study factors important for development of the disease.

\section{Amyloid and amyloidosis}

\section{History and definition}

The term amyloid was first introduced in the medical literature by the German pathologist Virchow in 1854 [7]. He identified a mysterious deposit in the nervous system that stained blue with iodine and sulfuric acid, similar to the reaction of starch. He named it corpora amylacea based on the Latin term "amylum" meaning starch. However, some years later a new insight into the biochemical character of amyloid was presented by Friedreich and Kekule when they found high proportion of nitrogen in amyloid and suggested that it was made up of proteins rather than of carbohydrates [8]. The major advances in the amyloid field occurred by the application of the histopathological dye Congo red in 1922 by Bennhold. Forty years later, Putchler improved Bennhold's method and still Congo red is the most specific and commonly used dye for detection and diagnosis of amyloid [9]. Amyloid stained with Congo red appears as a pink amorphous substance and upon examination in polarized light, it shows an apple green birefringence indicating an ordered structure [10]. Studies using transmission electron microscopy revealed that amyloid deposits have highly organized structure composed of fibrils with a diameter of $7-13 \mathrm{~nm}$ [11]. X-ray diffraction analysis of amyloid fibrils revealed a cross-beta structure 
[12]. Thus, by definition amyloid is an insoluble substance with a fibrillary appearance (Figure 1A), characteristic affinity for Congo red with green birefringence in polarized light (Figure 1B), and cross-beta pattern by X-ray diffraction analysis. This definition is general for all types of amyloid proteins, regardless of their amino acid sequence [13].
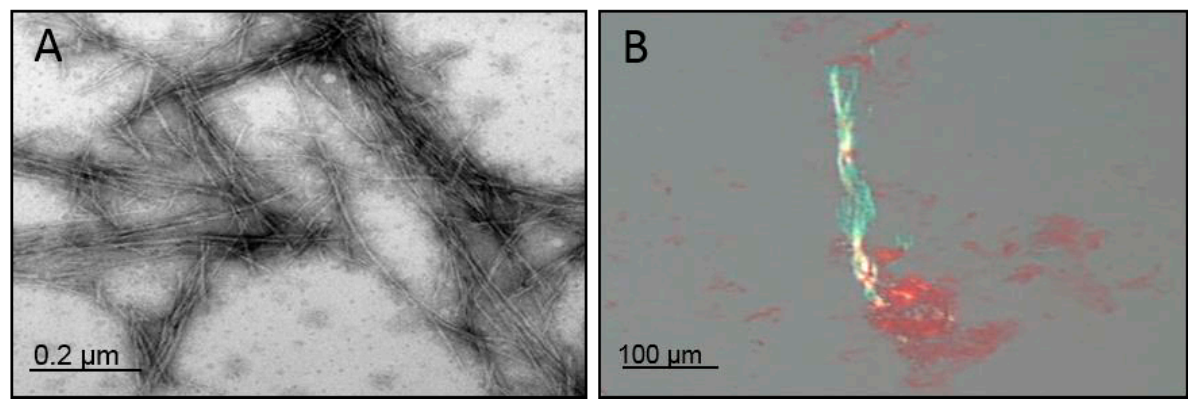

Figure 1. Appearance of amyloid. A. Transmission electron microscopy of the fibrillary structure of amyloid. B. Green birefringence appearance of Congo red stained amyloid in polarized light.

Although the major component of the amyloid deposit is the fibril forming protein, there are also non fibrillary components present in all forms of amyloid including, apolipoprotein E [14], serum amyloid P component [15] and heparan sulfate proteoglycan [16]. This suggests that the process of amyloid formation is very complex and not only dependent on the properties of the amyloidogenic proteins.

Amyloidosis is the name given to a group of diseases affecting humans and many other vertebrates that develop as a result of tissue damage from the deposition of predominantly extracellular amyloid fibrils. In general, amyloidosis is classified as either systemic or localized. In systemic amyloidosis circulating plasma proteins, including immunoglobulin fragments, transporters, acute phase reactants or other plasma components acquire a misfolded $\beta$-sheet-rich state and deposit in multiple organs such as heart, kidney, spleen and liver. In localized amyloidosis, amyloid deposits are confined to a particular organ where the precursor protein is produced. Examples of localized amyloidosis are deposition of amyloid in the brain in Alzheimer's disease and in the islets of Langerhans in type 2 diabetes [17]. At present, 36 proteins in human and 10 proteins in other vertebrates have been identified to form amyloid [18] and many are associated with serious disease symptoms (Table 1). 
Table 1. Examples of human amyloid diseases and their precursor proteins.

\begin{tabular}{|c|c|c|c|c|}
\hline Clinical Syndrome & $\begin{array}{l}\text { Amyloid } \\
\text { protein }\end{array}$ & Precursor protein & $\begin{array}{l}\text { Systemic and/ } \\
\text { or localized }\end{array}$ & Target organ(s) \\
\hline AL amyloidosis & AL & $\begin{array}{l}\text { Immunoglobulin } \\
\text { light chain }\end{array}$ & $\mathrm{S}, \mathrm{L}$ & All organs except CNS \\
\hline AA amyloidosis & AA & Serum amyloid A & $\mathrm{S}$ & $\begin{array}{l}\text { Kidney, GI tract, spleen and } \\
\text { liver }\end{array}$ \\
\hline $\begin{array}{l}\text { Cardiac } \\
\text { amyloidosis }\end{array}$ & ATTR & TTR, wild type & $\mathrm{S}$ & $\begin{array}{c}\text { Heart mainly in males, lung, } \\
\text { and ligaments }\end{array}$ \\
\hline Alzheimer's disease & $\mathrm{A} \beta$ & $\begin{array}{l}\mathrm{A} \beta \text { protein } \\
\text { precursor }\end{array}$ & $\mathrm{L}$ & CNS \\
\hline Type 2 diabetes & AIAPP & $\begin{array}{l}\text { Islet amyloid } \\
\text { polypeptide }\end{array}$ & $\mathrm{L}$ & Islets of Langerhans \\
\hline Parkinson's disease & A $\alpha$ Syn & $\alpha$-synuclein & $\mathrm{L}$ & CNS \\
\hline $\begin{array}{c}\text { Creutzfeldt-Jakob } \\
\text { disease }\end{array}$ & APrP & Prion protein & $\mathrm{L}$ & $\mathrm{CNS}$ \\
\hline
\end{tabular}

AL, Amyloid light-chain; AA, Amyloid A; ATTR; A $\beta$, Amyloid $\beta$; Amyloid transthyretin; AIAPP, Amyloid islet amyloid polypeptide; A $\alpha$ Syn, Amyloid $\alpha$-synuclein; APrP, Amyloid prion protein; CNS, Central nervous system

\section{Amyloid fibril structure}

Following synthesis, the peptide chain will fold into its predetermined secondary structure. The $\alpha$-helix and $\beta$-sheet are the two main secondary structures and they are stabilized by hydrogen bonding present within a peptide strand (intra-strand) or between strands (inter-strand), respectively. The $\alpha$-helix is a coiled strand and the most common and stable secondary structure. The $\beta$-sheet structure consists of pair of strands lying sideby-side with $4.7 \AA$ spacing. Hydrogen bonds between the carboxyl oxygen and the amino hydrogen of an adjacent strand stabilize the structure. The strands can be directed parallel or anti-parallel (N-terminus to C-terminus) of which the anti-parallel is more stable [19]. The aggregation of proteins into amyloid fibrils occurs as a result of alteration of their secondary structure i.e., the structure is changed from the native form to be dominated by cross- $\beta$-sheet [20]. Next, supramolecular associations between $\beta$-sheets at a distance of $10 \AA$ result in formation of cross- $\beta$-sheet pattern (Figure 2 ). The hydrogen bonds between the protein backbones and between the side chains in the $\beta$-sheets stabilize the structure $[2,20,21]$. Assembly of cross- $\beta$-sheet structures will then form into larger structures called protofibrils. Finally, the interaction between three to six protofibrils with a diameter of 2-5 nm will constitute the mature fibrils [22]. The stacking of $\beta$-sheets run parallel to the fibril axis while the $\beta$-strands are arranged perpendicular to the fibril axis in each sheet (Figure 2). 


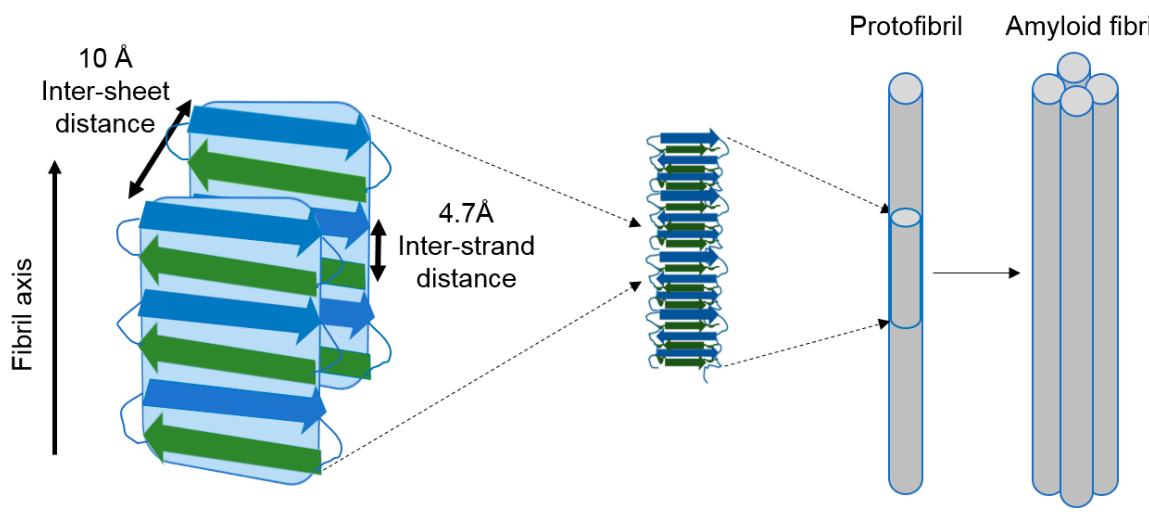

Figure 2. The cross $\beta$-sheet structure. In each sheet, the $\beta$-strands (green and blue arrows) are aligned perpendicular to the fibrilar axis with a spacing of $4.7 \AA$ and stabilized via hydrogen bonds. The cross- $\beta$ sheet structure is formed by association of $\beta$-sheets at a distance of $10 \AA$. The assembly of cross- $\beta$-sheet structures results in formation of protofibrils and further assembly of protofibrils will constitute the mature amyloid fibril.

\section{Protein folding and aggregation}

When the hydrogen bonds of the secondary structure have been formed, a protein must fold into a tertiary structure to become biological active. This structure is referred to as the native state of the protein $[2,4]$. Protein folding is a vital step and the thermodynamic process includes the interactions between the side chains of the amino acids, including ionic interactions, disulfide bonds, hydrophobic interactions, van der Waals forces and hydrogen bonds. Moreover, interactions between a protein and its environment also influence the shape and stability. Usually, polypeptides and small proteins are spontaneously folded into their native state, while folding of larger proteins take place via the formation of intermediates. To achieve the native conformation, cells have established systems that can assist during folding and refolding of proteins and also systems to degrade misfolded proteins. Molecular chaperones constitute an assisting system of proteins, which facilitate folding and assembly [23-25]. After the protein has reached its native state, it can unfold and adopt a new conformation, a misfolded state. To reverse this process the misfolded protein can be refolded by interaction with the chaperons. Alternatively, misfolded proteins are degraded by the proteasome or lysosome [1, 26, 27].

During folding, the hydrophobic effect is an important driving force. The hydrophobic residues of the polypeptide chain will occupy the core region of the folded protein and these intramolecular hydrophobic forces stabilize the structure. However, misfolded proteins can expose the hydrophobic residues at the surface and this result in intermolecular interactions between residues of the misfolded proteins, which might initiate aggregation [28]. Several types of aggregates can be formed namely; amorphous 
aggregates with a disordered conformation, $\beta$-sheet rich oligomers and amyloid fibrils with a highly structured conformation [2].

\section{The free energy landscape of protein folding and aggregation}

The protein folding process can be described as a multidimensional energy landscape where different conformational states of the protein are defined by the minimum free energy, known as Gibbs free energy. Proteins usually fold into the conformation in which the free energy is minimized, i.e. the native state. During folding, intermediates need to cross substantial energy barriers assisted by molecular chaperons in order to reach the thermodynamically most favorable state [2]. Generally the folding and aggregation process is determined by the competition between intramolecular and intermolecular interactions. When proteins are misfolded, molecular chaperons recognize the exposed hydrophobic amino acid side-chains and prevent intermolecular interactions, which promote correct folding into the native conformation [24, 25].

Misfolded proteins are prone to establish intermolecular interactions resulting in the assembly of various type of aggregates. Such aggregation processes are thermodynamically favorable, since the free energy of these aggregates are lower than the free energy of the misfolded protein. Among different types of protein aggregates, the amyloid fibril represent the folding state having a minimum of free energy and is therefore known as the thermodynamic ground state (Figure 3) [2, 29, 30].

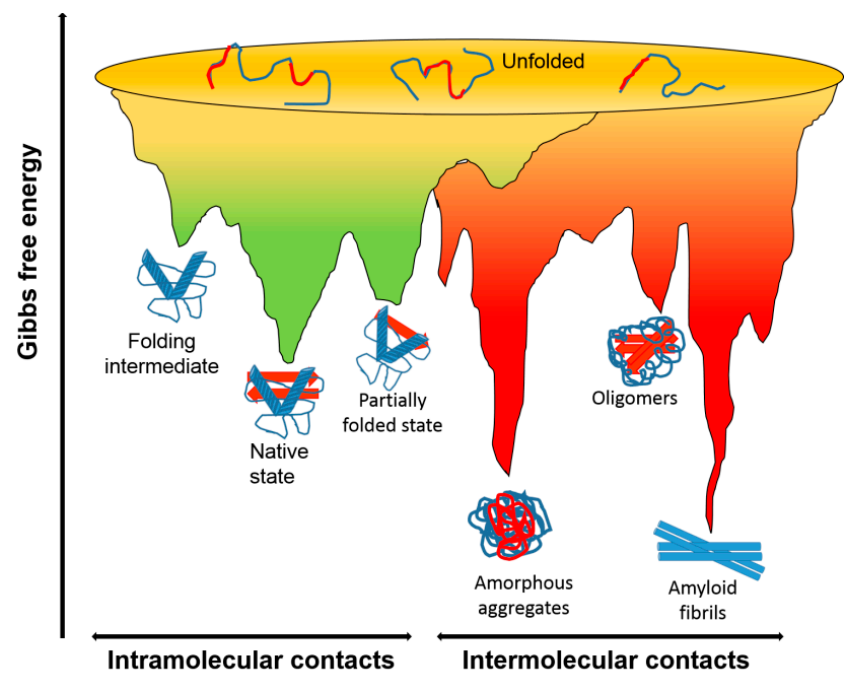

Figure 3. The energy landscape of protein folding and aggregation. Folding intermediate with high free energy are stabilized by energetically favorable intramolecular interactions towards the native state. Partially folded states are energetically favorable as compare to the unfolded state but with higher free energy than the native state. Intermolecular interactions between partially folded states might result in the formation of amorphous aggregates, oligomers, and amyloid fibrils. Modified from [24]. 


\section{Pathways of aggregation}

The amyloid fibril formation is a nucleation dependent pathway that can be divided into three phases; lag phase, elongation phase and plateau phase [26, 31]. During the lag phase, the soluble amyloid proteins are partially unfolded, misfolded or disordered. To form a nucleus, a minimum of three monomers interacting with each other via hydrogen bonds are needed. The nucleus is the smallest aggregate with the highest Gibbs free energy in the process and templates the misfolding of other monomers, in a process is referred to as primary nucleation. The formation of nuclei occurs during an extended time, from hours to a lifetime. Once the nuclei are formed they can serve as templates for fibril growth. This takes place during the elongation phase during which the fibrils extend by addition of monomers to the free ends. The slope of the elongation curve reflects the speed of the fibril formation. Finally, when most soluble proteins are converted into fibrils, the process reaches its equilibrium and enters the plateau phase (Figure 4) [3133].

Secondary pathways may also occur during aggregation such as amyloid fibril fragmentation and secondary nucleation. The fibril fragmentation will increase the number of fibril ends and consequently the speed of the fibrillation. Therefore, fragmentation has a significant impact on the kinetics during aggregation. Recently, it was suggested that the surface of fibrils could also act as template and catalyze the formation of more nuclei from monomers in a process called secondary nucleation (Figure 4) [34,35]. The secondary nucleation has been shown to occur in several amyloid proteins including A $\beta$ and IAPP $[36,37]$. However it should be kept in mind that the amyloid fibril formation process as described here originates from data collected from in vitro experiments performed in solutions usually containing highly pure and homogeneous peptides and proteins. In vivo, several factors including lipid membranes, electrolytes and other proteins may affect the aggregation [35]. 


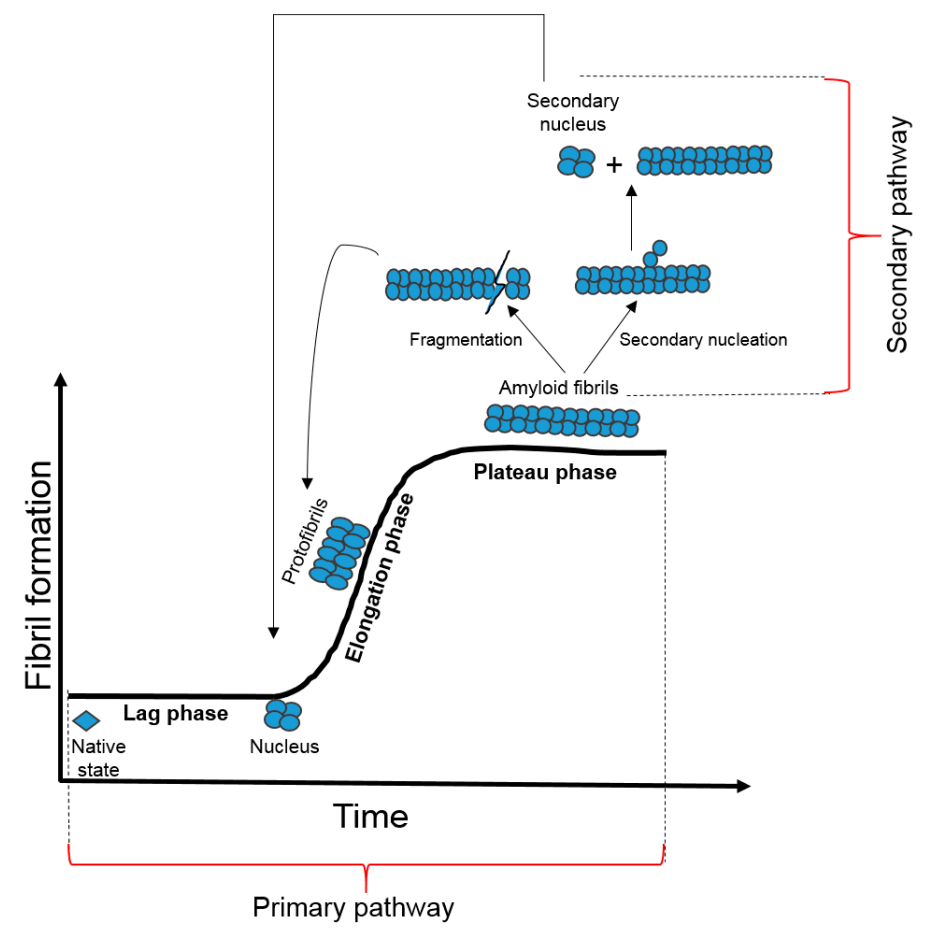

Figure 4. Pathways of protein aggregation. In the primary nucleation pathway, the interaction between monomers results in formation of an oligomeric nucleus during the lag phase. The propagation of the nucleus occurs in the elongation phase, and the process reaches its equilibrium in the plateau phase. The secondary pathway includes fragmentation and secondary nucleation. During fragmentation the fibrils are broken down leading to increased number of fibril ends and consequently increased number of site for addition of new monomers. During secondary nucleation, the fibril surfaces catalyze the formation of new nuclei from the monomers. Modified from [38].

\section{Seeding and cross seeding}

Primary nucleation is a energetically unfavorable process and therefore rather slow [2]. Several in vitro studies have shown that the formation of amyloid fibrils can be accelerated by administration of preformed fibrils (Figure 5) [39-41]. This phenomenon is called seeding during which the preformed fibrils act as template and induce a fast recruitment of normally folded monomeric proteins leading to an abolished or shortened lag phase. 


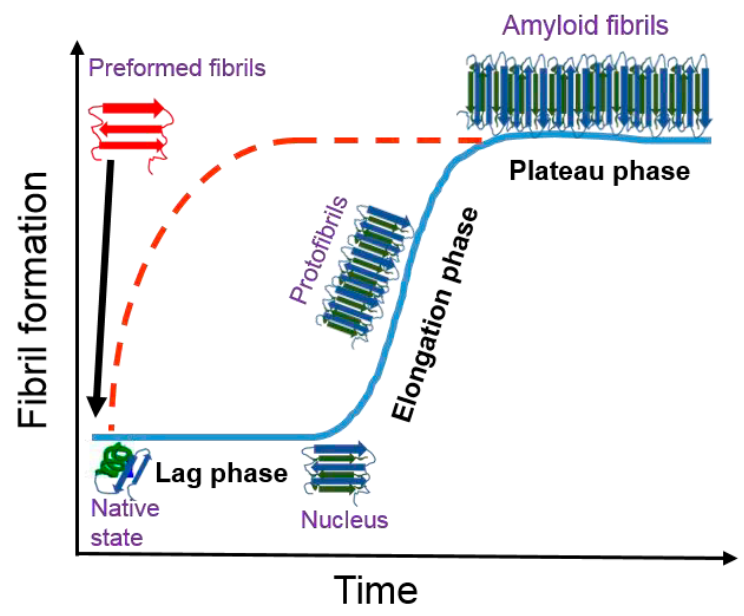

Figure 5. Seeding accelerates fibril formation. Administration of preformed amyloid fibrils will shorten the lag phase during amyloid fibril formation (dashed line).

Two distinct types of seeding have been identified, namely homologous and heterologous seeding (Figure 6). In homologous seeding or self-seeding, the fibril seed is identical to the soluble protein, while in heterologous seeding, or cross-seeding, the soluble and fibrillary proteins are different [31]. The efficiently seeding of IAPP (the fibril component in the islet of Langerhans) by the $\mathrm{A} \beta$ fibril is an example of cross-seeding [42].

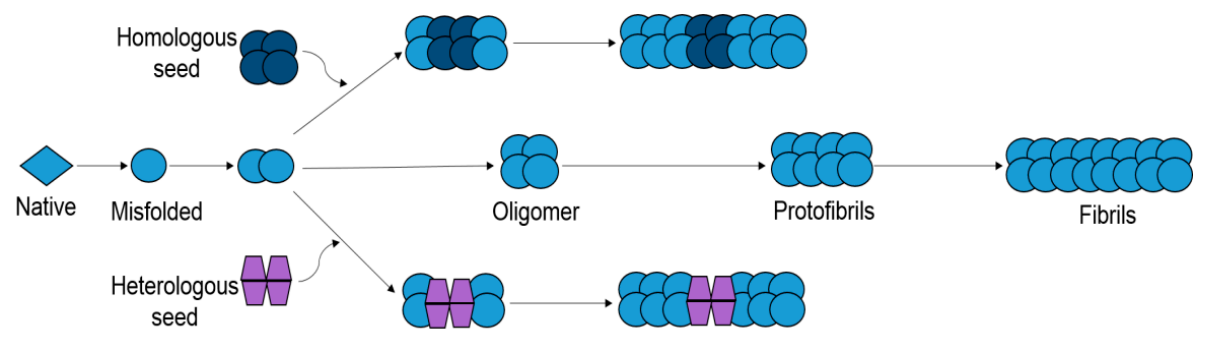

Figure 6. Schematic illustration of seeding and cross-seeding. Homologous seeding occurs when a protein in fibrillary form is the same as the soluble protein. During heterologous seeding or cross seeding, the seed and soluble proteins are different. Modified from [31].

Seeding is a key phenomenon describing a possible pathway for amyloid to spread in a tissue or organ and has been described as a part of the infectious process involved in prion diseases [43]. Prion diseases, also called transmissible spongiform encephalopathies, are a group of neurodegenerative disorders that affect the nervous system in human and 
animals [44]. The most common form of human prion disease is Creutzfeldt-Jakob disease. The prion protein $(\mathrm{PrPc})$ is normally a cellular protein with an $\alpha$-helix rich structure that is present on the cell surface. During misfolding, PrPc is converted into a $\beta$-structure-rich insoluble form known as the scrapi form $(\mathrm{PrPsc})$, which has the capacity to produce identical or similar copies of itself by self-propagation. Thus, it is transmissible and able to induce the misfolding of normal cellular prion proteins and spread the disease $[45,46]$.

\section{Lipid membrane and amyloid formation}

The protein aggregation process is highly dependent on the environmental conditions, such as $\mathrm{pH}$, temperature and ionic strength. Beside these factors, the presence of surfaces such as membranes have been shown to affect the aggregation process [47]. Natural membranes consist of a phospholipid bilayer bound with proteins and small molecules such as cholesterol and carbohydrates. Due to the fact that most proteins are exposed to biological membranes in their biological context, they are considered important factors that might affect amyloidogenesis. Therefore, model membranes that closely mimic natural plasma membrane of mammalian cells are excellent models for studying the interaction between membrane and amyloid proteins [48]. Different properties of the lipid bilayer has been shown to affect the fibrillation of amyloid proteins such as; lipid composition, size, shape and curvature [49-51].

The importance of interaction with lipid membrane for protein aggregation has been extensively studied in vitro for different amyloid proteins including $\mathrm{A} \beta$ and $\alpha$-synuclein $[49,52,53]$. It is suggested that membranes affect the amyloid fibrillation through a number of different mechanisms; for example by increasing the local concentration of the protein, unfolding the peptide and altering the secondary structure of protein in an aggregation-prone manner [54]. It has been shown that the interaction between the lipid membrane and the $\mathrm{N}$-terminal part of the $\alpha$-synuclein molecule results in conformational changes from random coil to $\alpha$-helix that can stabilize intermolecular interactions, which favor the conversion to $\beta$-sheet conformation and promote aggregation [55]. Moreover, the rate of primary nucleation of $\alpha$-synuclein in the presence of lipid vesicles is enhanced, which promote its conversion from soluble state to aggregated form [52]. Several studies of the interaction between lipid membrane and the $\mathrm{A} \beta$ peptide also showed that lipids might affect conformational changes from an $\alpha$-helical to $\beta$-sheet structure and consequently accelerate the fibrillation [56-58]. Furthermore, in vitro fibrillation of $A \beta$ requires higher concentration of peptide than the corresponding process in vivo [36, 59] and many studies suggest that the local concentration of $A \beta$ might increase upon interaction with lipid membrane, and consequently this could be an explanation of the differences in concentrations required for $\mathrm{A} \beta$ fibrillation [60]. 


\section{Amyloid fibril polymorphism}

In general amyloid fibrils are capable of forming multiple fibril morphologies, i.e., they are polymorphic. Fibril polymorphism can be due to differences in the number of protofibrils or in the orientation of the protofibrils, as well as differences in their internal structure [61, 62]. Variation in fibril growth conditions such as temperature, $\mathrm{pH}$, and composition of the solution may alter the rate of nucleation, elongation and secondary nucleation, which favor the production of a specific fibril morphology [63]. For example, gentle agitation of $\mathrm{A} \beta 40$ fibrils at $24^{\circ} \mathrm{C}$ and $\mathrm{pH} 7.4$ will give rise to the predominant striated ribbon morphology, while the same growth condition without agitation results in a twisted morphology [64]. Intracellular factors such as molecular chaperons and lipid content could also affect the fibrillar morphology [62]. Fibril morphology could also be a replication of the morphology induced by a seed. One example is the prion proteins. Prion has been shown to have different phenotypic variants known as strains [65]. Such strains with different conformation, can template their own morphology during propagation by recruitment of surrounding protein molecules [21, 66]. It has been shown that different prion strains when inoculated into a new host cause disease with specific properties such as severity of changes in the brain or affected area of the brain [65, 67].

\section{Amyloid toxicity}

In multicellular organism there is a homeostasis between cells growth and death. Redundant or damaged cells are programmed to die to avoid tissue damage and make room for functional cells. There are many types of cell death, but two extremes; necrosis and apoptosis, are often compared [68]. Necrosis is an acute process that occurs when cells are exposed to extreme conditions such as altered temperature, decreased oxygen levels or exposure to toxins. This might lead to energy depletion, alteration of the internal cellular environment and plasma membrane rupture. The necrotic cell will swell and lose integrity, which results in the release of the cell content to the external environment. Eventually, accumulation of cellular debris will lead to inflammation and tissue damage (Figure 7) $[69,70]$. Apoptosis is a genetically programmed pathway that is necessary for maintaining a balance of the number of cells in the body and for removal of infected or mutated cells. Morphologically, apoptosis is characterized by nuclear fragmentation, chromatin condensation, shrinkage of cellular volume along with blebbing of the plasma membrane. Biochemically these morphological features are regulated by activation of proteases, named caspases in a cascade-like pathway. Ultimately, apoptotic cell death leads to formation of condensed bodies known as apoptotic bodies, which are recognized and engulfed by scavenger cells, mainly macrophages (Figure 7) [69, 71]. When analyzing cell death in cell cultures, an alternative outcome of apoptosis called secondary necrosis might be detected. When the apoptotic program is completed, cellular 
disintegration and release of cell contents might occur due to the absence of phagocytosing cells [72].

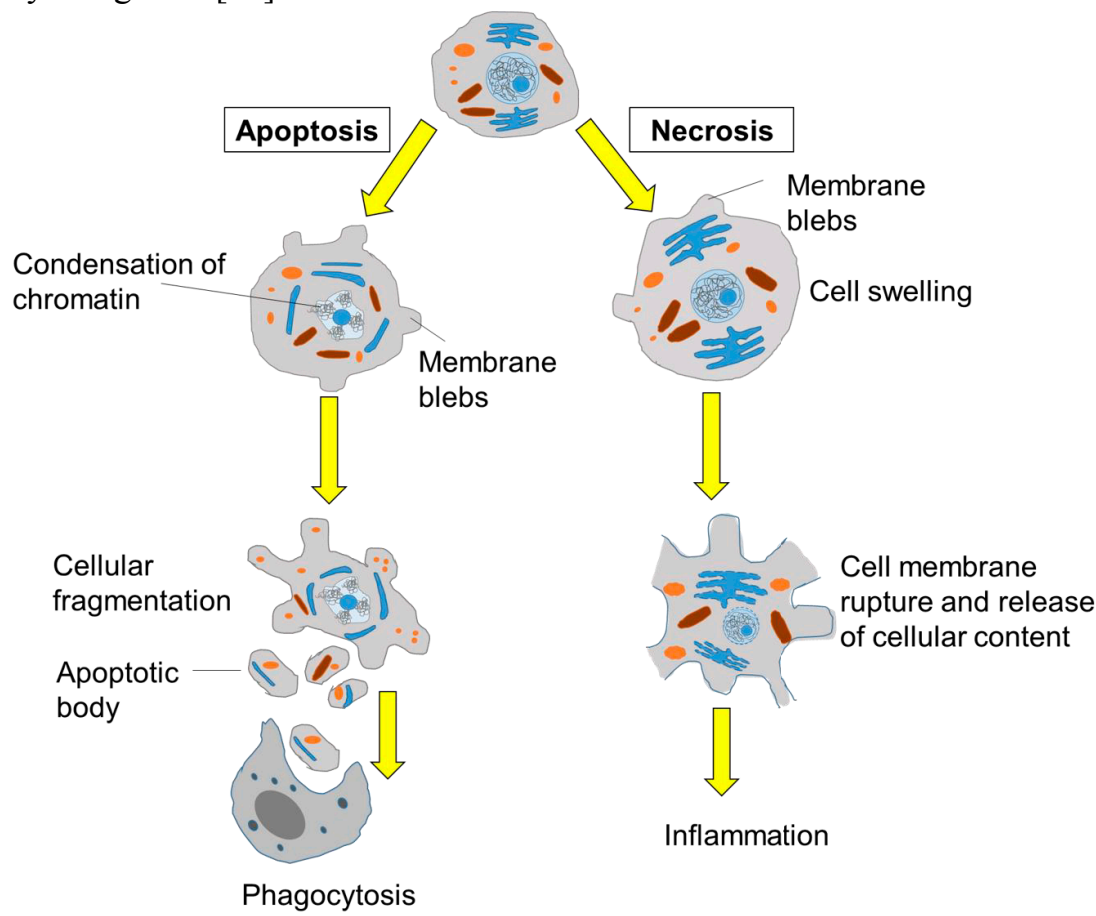

Figure 7. Graphic presentation of morphology during cell death. To the left, the apoptosis pathway is represented with the characteristic condensation of chromatin, shrinkage of cell volume, appearance of cell membrane blebs and formation of the apoptotic bodies which subsequently are phagocytosed. To the right, the necrosis pathway shows the swelling of the cell and its organelles, followed by rupture of the plasma membrane that results in release of cellular content and subsequent induction of tissue inflammation.

The mechanism of amyloid induced cell toxicity has been widely studied [27, 73, 74]. It is evident that oligomers are the most toxic species and they are able to cause direct cellular damage [27]. The oligomers are either produced during amyloid formation or released from mature fibrils [75]. The exact mechanism by which amyloid induces cell toxicity is not clear. However, structural characterization of oligomers indicate that the heterogeneity of these species in the term of size and structure affect their toxicity. Exposure of hydrophobic groups at the surface of the oligomer seems to be an important factor determining the interactions with phospholipid bilayers, different protein receptors and other cell surface components. This might result in reduced receptor activity, increase in membrane permeabilization, formation of pore-like structures and disruption of ion homeostasis causing e.g. $\mathrm{Ca}^{2+}$ influx $[27,76,77]$. The small size of oligomers and the presence of more active ends, which improve their interaction with cellular targets also 
determine their toxicity [78]. Cellular uptake of oligomers by endocytosis or phagocytosis, cause intracellular accumulation of undegradable species and eventual impairment of cellular degradation systems, generation of reactive oxygen species, mitochondrial dysfunction and subsequently induction of apoptosis or other forms of cell death [79].

\section{Amyloid detection}

\section{Congo red}

Congo red (Figure 8), an aromatic sulfonated azo dye, was the first agent used for diagnosis of amyloid diseases and still it is the gold standard dye due to its high sensitivity and specificity for amyloid structure [80]. The binding between the dye and the amyloid gives rise to the apple-green birefringence when the stained amyloid is visualized in cross polarized light and typical pinkish color in bright light [81]. Congo red only binds protein aggregates with an extensive cross $\beta$-pleated sheet conformation, but lacks ability to distinguish different types of amyloid structures. Therefore the heterogeneity of amyloid aggregates found by other methods could not be detected by Congo red [80].

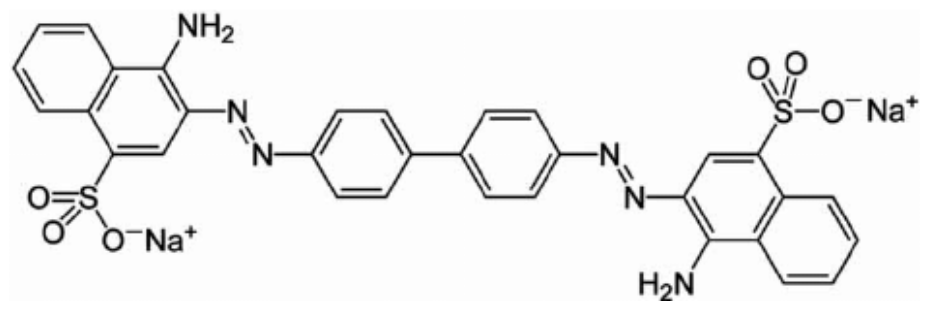

Figure 8. Chemical structure of Congo red.

\section{Luminescent conjugated oligothiophenes}

Luminescent conjugated oligothiophenes (LCOs) are conformation sensitive probes that are able to detect and differentiate between different structures and conformations of protein aggregates. The thiophene unit is a heterocyclic aromatic compound with the formula $\mathrm{C}_{5} \mathrm{H}_{4} \mathrm{~S}$, which constitute the conjugated backbone. During synthesis of oligothiophene, the thiophenes are linked together by a carbon-carbon single bond which is formed by boronic acid with a halide using a palladium catalyst [82].

Different LCOs are characterized by variant number of thiophenes in the backbone. The fluorescent spectrum of the LCO is determined by the length of the thiophene backbone and the chemical substitution along the backbone. Moreover, the biding propensity varies 
depending on the amyloid structures [82, 83]. The twistable thiophene backbone makes the molecule conformational sensitive and produce emission spectra that changes depending on the conformation of the amyloid [82]. LCOs have been used to discriminate between different protein aggregates including different prion strains and $\mathrm{A} \beta$ aggregates $[82,84]$. Recently, a thiophene based ligand has been developed that selectively binds to Tau aggregates [85].

In this thesis, the tetrameric formic thiophene acetic acid (qFTAA) and the heptameric formic thiophene acetic acid (hFTAA) were used (Figure 9). The first letter of the abbreviation stands for the number of thiophene rings. The second letter (F) indicates the substitution of two end-thiophenes moieties by formic acid and the last two letters (AA) indicate the substitution of the thiophene backbone by acetic acid [82].

A<smiles>O=C(Cc1cc(-c2ccc(C(=O)O[Na])s2)sc1-c1ccc(CO[N+](=O)[O-])s1)O[Na]</smiles>

B

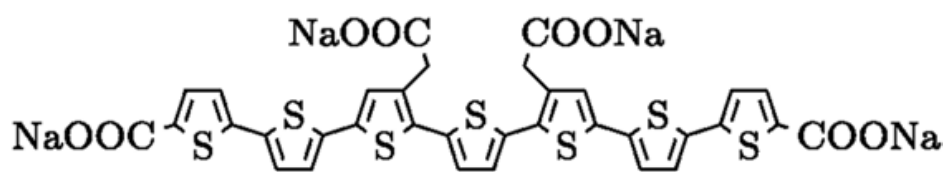

Figure 9. Chemical structure of Luminescent conjugated oligothiophenes (LCOs). A. qFTAA and B. hFTAA.

\section{AA Amyloidosis}

AA amyloidosis is one of the most prevalent forms of systemic amyloidosis and is found in humans and in over 50 animal species. The precursor protein is the acute phase protein serum amyloid A (SAA) [5, 6]. In human, AA amyloidosis occurs as a consequence of long standing inflammatory diseases e.g. tuberculosis, rheumatoid arthritis and familial Mediterranean fever [5]. The local inflammatory cells such as macrophages and neutrophils secrete proinflammatory cytokines including tumor necrosis factor (TNF)- $\alpha$, interleukin (IL)- $1 ß$ and IL-6 into the bloodstream. The inflammatory cytokines act mainly on hepatocytes and increase their production of serum amyloid A [86, 87]. Although high level of SAA is required for development of AA amyloidosis, only a fraction of patients will develop the disease. This indicates that additional factors such as genetic background and environmental factors might be important [5]. 


\section{The acute phase response}

The immune system is divided into the innate and adaptive immunity. Innate immunity or non-specific immunity is the first defense to any foreign entry in the body, while the adaptive immunity is specially targeted to particular pathogens and is carried out by lymphocytes through the generation of antibodies and cell-mediated immune responses [88].

The innate immunity is composed of two lines of defense namely the physical barriers as well as the inflammatory response. The skin together with the mucous membrane is the primary physical barrier. Sweat glands and other skin secretions along with mucous, bile, gastric acid, saliva and tears, prevent the entrance of microorganism into the body [89].

The inflammatory response is involved in the defense against any foreign entry and the subsequent resolution of inflammation and repair of damaged tissue. The inflammatory response can be acute or chronic based on the duration and intensity of the inflammatory stimuli. Acute inflammation is a short-term reaction, lasting from minutes to days, while chronic inflammation is a long term inflammation, lasting from weeks to months and even years [90]. The acute phase response is an essential part of the innate immune system, which is activated by different stimuli such as trauma, infection and stress. The possible outcomes of acute inflammation are complete resolution, scarring, abscess formation and progression to chronic inflammation. Thus if the acute phase could not be resolved, it results in chronic inflammation. Persistent injury or infections, prolong exposure to toxic agents and autoimmune diseases are examples of conditions that might result in chronic inflammation [91]. Chronic inflammation is initiated by lymphocytes, macrophages and plasma cells, while cells harboring specific pattern-recognition receptors able to recognize any pathogens such as tissue macrophages, neutrophils and mast cells constitute the acute phase response [88]. The recognition stimulates activation of more macrophages and induces the secretion of proinflammatory cytokines, particularly IL-1 13 , IL- 6 and TNF- $\alpha$, as well as several chemokines. The production of proinflammatory cytokines affect the production of the acute-phase proteins (APPs). The APPs are soluble components of the innate immune system that are produced in the liver and release into the blood [92]. When the plasma concentration of APPs is increased, these proteins facilitate the recognition of pathogens by binding to the polysaccharide components of the pathogen's cell wall. This opsonization process improves the recognition by phagocytic cells such as macrophages. Consequently, APPs induce the migration of phagocytes to the affected area and enhance phagocytosis. The two major APPs in human are C-reactive protein (CRP) and serum amyloid A (SAA) [92]. 


\section{Interleukin-1 $\beta$}

IL-1 $\beta$ is an early response cytokine usually produced by activated macrophages. It has a crucial role in the pathogenesis of several inflammatory disorders, such as rheumatoid arthritis and atherosclerosis [93]. IL-1 $\beta$ is synthesized as an inactive precursor, pro-IL$1 \beta$, that undergoes activation via enzymatic cleavage by caspase- 1 . The activation of caspase-1 occurs via assembly of multi-protein complexes of the NALP family of inflammasomes [94]. SAA has been shown to provide a signal for production of pro-IL$1 \beta$ as well as activation of the Nod-like receptor protein 3 (NLRP3) inflammasome [95]. Moreover, it has been shown that, the production of IL-1 $\beta$ can be independent of inflammasome activation [96, 97]. For example in caspase-1-deficient mice, the production of IL-1 $\beta$ is not inhibited [96], since other proteases such as cathepsin $\mathrm{C}$ are also capable of processing pro-IL-1 $\beta$ [97].

\section{Serum amyloid A}

As described above SAA, is an acute phase reactant produced in the liver and transported in the circulation bound to high density lipoprotein (HDL). Under normal conditions the serum concentration of SAA is low but during inflammation, the concertation is dramatically increased from $1 \mu \mathrm{g} / \mathrm{ml}$ to $1 \mathrm{mg} / \mathrm{ml}$, which leads to a partially replacement of apoA-I (a major protein constituent of HDL) by SAA [98]. The major function of SAA is not clear but several physiological functions have been proposed, such as a role in modulation of the immune response and in regulation of reverse cholesterol transport [ 98 , 99]. The SAA constitutes a family of proteins composed of 103-104 amino acids with poor aqueous solubility. They are encoded by closely related genes with very strong conservation throughout the vertebrate evolution. In humans and mice, SAA is encoded by 4 genes (SAA1-SAA4) and the two main isoproteins in humans are SAA1 and SAA 2 and in mice are SAA1.1 and SAA2.1 [100]. The AA amyloidosis arises from misfolding and aggregation of SAA1 and SAA2 of which SAA1 is the predominant precursor protein. In mouse, the SAA2.1 protein is $94 \%$ identical to SAA1.1, and it has been shown that both isoforms are induced in approximately equal quantity during inflammation. However, only SAA1.1 forms AA amyloid indicating that these small differences in amino acid sequence have major impact on the amyloidogeneity of the proteins [101].

SAA is synthesized as pre-SAA consisting of 122 amino acids, which includes an 18amino acid signal peptide. The signal peptide is cleaved during secretion, which results in the mature form of SAA1 with 104-amino acid. The monomeric structure of human SAA1 is predicted to consist of four antiparallel $\alpha$-helices; helices 1 (aa 1-27), 2 (aa 3247), 3 (aa50-69), 4 (aa 73-88) and a C-terminal tail (aa 89-104) (Figure 10A) [102]. The $\mathrm{N}$-terminal region of SAA1 binds to the lipid surface of HDL, while the $\mathrm{C}$-terminal region stabilizes the overall structure (Figure 10B). Removal of the C-terminal region results in 
aggregation of the N-terminal fragments and AA amyloid formation [103, 104]. In AA amyloidosis, amyloid deposits consists of proteolytic fragments of different length and different isoelectric points [105]. The AA protein with 76-residiues is the most common aggregation prone fragment found in amyloid deposits isolated from renal glomeruli [106]. It has been shown in vitro that digestion of recombinant human SAA1 by the lysosomal protease cathepsin B generates the 76-residue fragment [107]. Interestingly, about $10 \%$ of the patients with AA amyloidosis have amyloid deposits composed of $\mathrm{N}$ terminal fragments of around 100 and 44 residues, which are deposited in the renal medulla and blood vessel walls. These patients do not develop proteinuria since amyloid deposits are excluded from glomeruli [108].

A

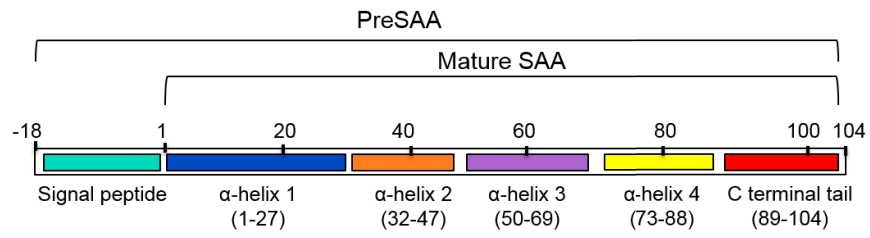

B

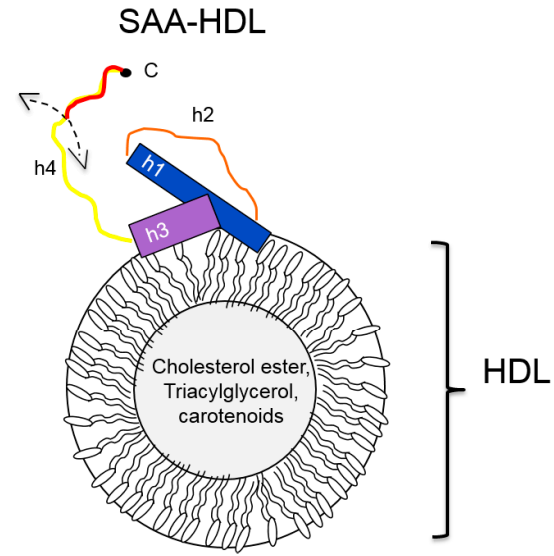

Figure 10. The serum amyloid A protein. A. Linear schematic presentation of human SAA1. A signal peptide of 18 amino acids is located in the N-terminal. The mature SAA1 protein has 104 amino acids containing $4 \alpha$-helices (h1-h4) and a C-terminal tail [103]. B. Suggested model for SAA interaction on HDL showing that SAA binds to HDL through amphipathic $\alpha$-helices h1 and h3. Modified from [104]. 


\section{Diagnosis and treatment of AA amyloidosis}

AA amyloidosis is a systemic disease where amyloid deposits are found in most organs typically in kidneys, spleen and liver. Proteinuria is usually the first clinical sign of the disease $[5,109]$.

The only way to diagnose systemic amyloidosis is by analysis of a tissue biopsy. The abdominal adipose tissues usually contain amyloid deposits and is easily collected but biopsy of gastrointestinal mucosa or kidney can also be used [5]. As mentioned above, the presence of amyloid is detected by Congo red staining and the deposits in AA amyloidosis usually have strong affinity. There are also alternative detection methods such as staining with thioflavin $\mathrm{T}$ or $\mathrm{S}$ but this method requires analysis in fluorescence microscope [110]. The important aspect for diagnosis of systemic amyloidosis is to determine the amyloid type. Usually immunohistochemistry can be performed with commercially available antibodies, [111] which are available for AA amyloidosis [5].

Like all amyloid diseases, there is no amyloid-specific therapy for AA amyloidosis. However, by controlling the inflammation using e.g., anti-TNFs, IL-1 $\beta$, and IL-6 blockers, the SAA level can be suppressed, which eliminate the risk of developing the disease $[5,112]$. Today the knowledge about AA amyloidosis and the mechanism of the formation of amyloid fibril is expanding and there are many specific treatments under development. In some treatments, the fibrils themselves are the main target, while molecules that are implicated in the pathogenesis of AA amyloidosis such as heparan sulfate [113] and serum amyloid P [114] are the targets of other suggested treatments.

\section{Mouse models of AA amyloidosis}

Since AA amyloidosis is caused by long standing inflammation, it can be induced in susceptible animals. As the mature proteins encoded by $S A A 1$ and $S A A 2$ are highly conserved between mouse and human, the mouse is an excellent model for studies of AA amyloidosis [115-117]. The inflammation inducible murine AA models have been extensively used to study AA amyloidosis. In these models, inflammation is induced by a variety of inflammatory stimuli such as casein, Freund's adjuvant, lipopolysaccharides and silver nitrate [118-121]. This results in production of inflammatory cytokines (IL-6, IL-1 $\beta$ and TNF- $\alpha$ ) that stimulate the acute phase response. Using silver nitrate as an inflammatory stimulus, AA amyloid deposits occurs after $>5$ weeks indicating the time frame for the lag phase [122]. However, addition of extract of amyloid laden tissue, referred to as amyloid enhancing factor (AEF), simultaneously with inflammation, accelerate amyloid formation from weeks to days [123]. In this rapid model, amyloid 
deposition starts in the marginal zone of the spleen followed by deposition in the liver and much later in the kidneys [124].

\section{Substances with amyloid enhancing properties}

As mentioned above, AEF is able to shorten the lag phase and accelerate the amyloid formation [125]. Of note, AEF also has the ability to cross-seed between different species. It has been shown that spleen homogenates from patients with AA or AL amyloidosis can induce amyloidosis in inflamed mice [126]. Acceleration of AA-amyloid deposition is also possible by introducing synthetic amyloid-like fibrils made from different amyloid proteins as well as natural amyloid-like fibrils such as silk and curli. Consistent experiments suggest that the biologically active component in AEF is the amyloid fibril itself that act as a seed [125, 127, 128]. Interestingly, there are also non-fibrillary substances with potential to accelerate amyloid formation in inflamed mice, for example, polyethylene glycol (PEG). Since PEG is not an amyloid template, the mechanism for PEG-induced amyloid enhancement should be different from that of AEF. PEG do not induce an inflammatory response but has been shown to affect the function of macrophages and mast cells by accumulation in lysosome, which might affect the cellular processing of SAA [129]. Moreover, as already mentioned above, lipid membranes are able to catalyze fibrillation of different amyloid proteins such as $A \beta$ and $\alpha$-synuclein in vitro $[49,130,131]$.

\section{Structure of the spleen}

In the mouse model of AA amyloidosis, the spleen is the first organ to be affected by amyloid. The spleen is a lymphoid organ, rich in immune cells, including macrophages, lymphocytes and dendritic cells. The major function of the spleen is to identify blood borne pathogens, remove dying red blood cells, regulate erythrocyte homeostasis and inflammatory responses [132]. During inflammation, splenic macrophages increase the secretion of proinflammatory cytokines such as IL-6 and TNF- $\alpha$ as well as the antiinflammatory cytokine IL-10. Thus spleen plays a central role in the systemic immune reactions [133-135].

The spleen has a unique architecture comprising two main compartments, the white pulp and the red pulp (Figure 11). The white pulp consists of follicles, the periarterial lymphatic sheath (PALS) and the marginal zone. The marginal sinus is a vascular channel that separate the marginal zone from the follicles. Blood enters the spleen through the splenic artery that branches into smaller arteries, called central arteries that continue into the end capillaries. Around the splenic artery lymphoid tissue called PALS is located, which mainly contains lymphocytes and macrophages. The PALS is surrounded by an area called the marginal zone, in which follicles contain B-cells are situated. The marginal 
zone forms the border between the white and red pulp and is predominantly made up of macrophages [132]. Two different types of macrophages populate the marginal zone; metallophilic marginal zone macrophages (MMZMs) and marginal zone macrophages (MZMs). These are present at the inner and outer border of the marginal sinus, respectively. Both MZMs and MMZMs are cells with high ability to phagocytose blood borne pathogens [136]. These macrophages appear only after birth and are found in their location between postnatal days 21-28. The exact origin of these populations of macrophages is still unclear, although it has been shown that they can develop from bone marrow monocyte precursors cells [137]. They express a unique set of pattern recognition receptors and are able to remove most types of bacteria and viruses entering the marginal zone. MZMs are characterized by expression of the C-type lectin SIGNR1 and type I scavenger receptor called the macrophage receptor with collagenous structure (MARCO). In contrast, MMZMs are characterized by expression of the adhesion molecules SIGLEC1 and MOMA-1 [138].

The main part of the spleen is made up by the red pulp where the red blood cells undergo a quality control and consists of cords and venous sinuses. The end capillaries that are branches of the central arteries allow the red blood cells to flow into the surrounding tissues called venous sinuses and then transport them to the collecting vein, which join into the splenic vein. The venous sinuses are lined by endothelium with an unusual discontinuous structure. Between the end capillaries and venous sinuses areas of tissue called cords, which contain red pulp macrophages (RPMs), are situated [132, 139]. RPMs are characterized by expression of $\mathrm{F} 4 / 80^{\text {high }} \mathrm{CD} 68^{+} \mathrm{CD} 11^{\text {low }}[138]$. RPMs originate from the primitive yolk sac and fetal definitive hematopoiesis and locate in the red pulp between postnatal days 14-21. After depletion, RPMs repopulate the red pulp by bone marrow monocytes [137]. The role of RPMs is to filter the blood from senescent erythrocytes. In addition RPMs control the iron homeostasis and prevent autoimmunity by production of anti-inflammatory cytokines such as IL-10 and by induction of innate and adaptive immunity $[132,140]$. 


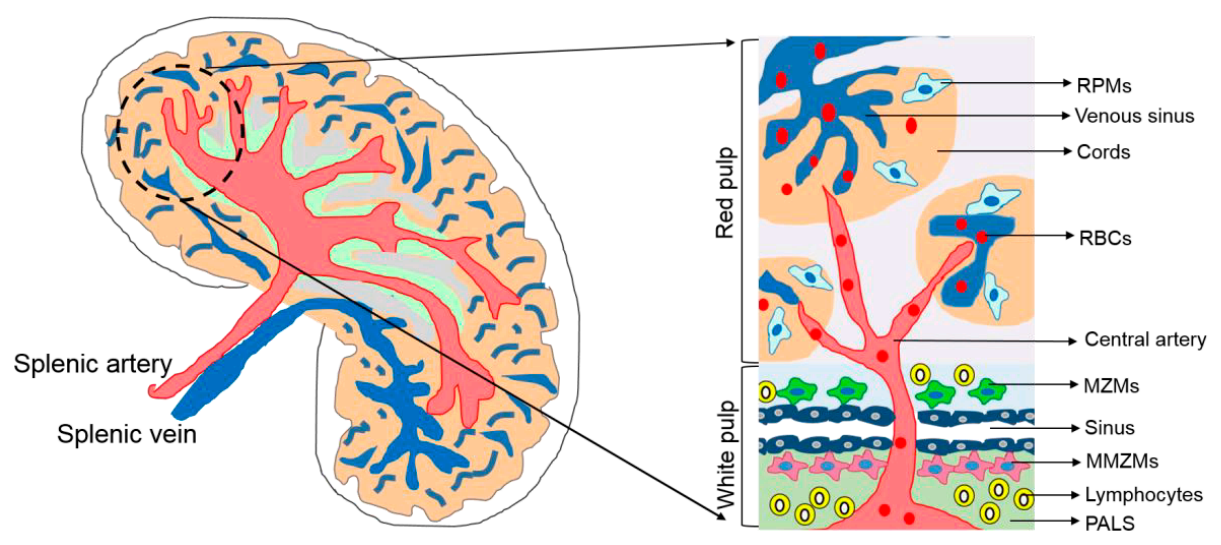

Figure 11. Structure of the spleen. Spleen comprises two main compartments; red pulp and white pulp. The red pulp consists of venous sinuses and cords, which contain red pulp macrophages (RPMs) (shown in light blue). Marginal zone macrophages (MZMs) (shown in green) and metallophilic marginal zone macrophages (MMZMs) (shown in purple) are located in the outer an inner part of the marginal sinus, respectively. Red blood cells (RBCs) are shown in red and periarterial lymphatic sheath (PALS), which consists of lymphoid tissues surrounding the central arteries are shown in light green. Modified from [136].

\section{Macrophages in AA amyloidosis}

Tissue resident macrophages has been shown to be involved in the pathogenesis of amyloid diseases [141, 142], and macrophages are frequently found in close association with the amyloid. Since macrophages contain a broad range of proteases able to proteolytically cleave amyloid precursor proteins, they might promote amyloidogenesis. On the other hand, amyloid degradation is a possible target for macrophage derived proteases [143, 144]. Thus, macrophages have been proposed to be involve in both formation and degradation of the amyloid. [124, 145, 146].

\section{Amyloid clearance}

Studies performed in the murine model of AA amyloidosis have shown that amyloidosis is a reversible process. If inflammation ceases, the amyloid can be almost completely cleared form spleen and liver within 6-8 months [147, 148]. However re-induction of amyloidosis by repeating the inflammatory stimulus results in an excessive amyloid deposition [148]. Amyloid has been shown to be engulfed by macrophages indicating that they are possibly involved in the clearance of amyloid [144, 149]. Moreover, it has been shown that immunological mechanisms are involved in the clearance of amyloid in the experimental mouse model of AA amyloidosis, since antibodies against AA amyloid are developed during clearance [117]. 


\section{Aims}

The general aim of the studies included in this thesis was to increase the knowledge of mechanisms important for AA amyloid development using a mouse model.

We specifically aimed to:

- Study the function and fate of the splenic macrophages during AA amyloid formation.

- Elucidate the significance of lipid membrane in development of AA amyloidosis.

- Characterize the conformational properties of AA amyloid deposits by using different seeds.

- Study AA amyloid-induced cytotoxicity. 


\section{Comments on Methods}

This section contains the theoretical background and some considerations regarding the methods used in Paper I-III. For complete descriptions of all materials and methods used, see the respective paper.

\section{Mouse model of AA amyloidosis}

The mouse (Mus musculus) is the most common animal model for AA amyloidosis showing similar amyloid distribution pattern and organ damage as in human [2]. Outbred female NMRI mice were used in this thesis. To achieve rapid amyloid accumulation we decided to, besides inducing inflammation, use $\mathrm{AEF}$, which was injected in the tail vein. Inflammation was induced by injection of $1 \% \mathrm{AgNO}_{3}$ that is well-known for its potent ability to induce acute inflammation. It was injected subcutaneously directly after AEF injection. To maintain inflammation the injections were performed at day 0 and then repeated once a week. Injection of $\mathrm{AgNO}_{3}$ results in elevation of the precursor protein $\mathrm{SAA}$, which peaked 24 hours after injection [150]. Injection of $\mathrm{AgNO}_{3}$ may cause small ulcers at the site of the injection due to its toxicity. To minimize the risk of such ulcers, each dose of $\mathrm{AgNO}_{3}$ was distributed at several places. Mice that developed ulcers were kept in separate cages and treated with the antifungal drug methyl-rosanilin.

\section{Ethical consideration}

The animal experiments were approved by the Animal Ethics Committee at Linköping University (Permit numbers 85-11 and 120-10).

All experiments were performed with focus on welfare of the animal and with the goal to cause as little suffering as possible. The animals were excluded from the experiments and sacrificed according to the animal ethics regulation if weight loss of more than $10 \%$ or deteriorated general condition was observed. All injection were performed on anesthetized animals. The intravenously injected AEF and liposomes were not toxic and did not cause any local reaction. No symptoms nor weight loss due to development of amyloid was detected in animals during the study period. 


\section{Amyloid staining and grading}

\section{Congo red}

For fast detection of amyloid, spleen or liver smears were stained with Congo red to rapidly observe the presence of amyloid. This method is very convenient and trustable. We used small piece of fresh tissue, which was compressed and spread between two glass slides, fixed in formalin and stained with Congo red. For grading of amyloid and morphological studies, frozen spleen sections were stained with Congo red and counterstained with Mayer's hematoxylin. Congo red can be visualized both by light microscopy using a polarization filter and by fluorescence microscopy. Amyloid displays red fluorescence when excited at wavelengths between $530-585 \mathrm{~nm}$ and is detected by emission above $600 \mathrm{~nm}$ [151].

Amyloid was graded blinded by two independent observers using a semi-quantitative method described by Lundmark et al [125]. Briefly, the amyloid load graded 1+ was defined as detection of one or two small deposits in the whole section, $2+$ as amyloid localized in the follicles in a limited area, $3+$ as moderate amount of amyloid deposits found around almost all follicles, and $4+$ as extensive amyloid deposits found around all follicles and often extending into the red pulp (Figure 12).

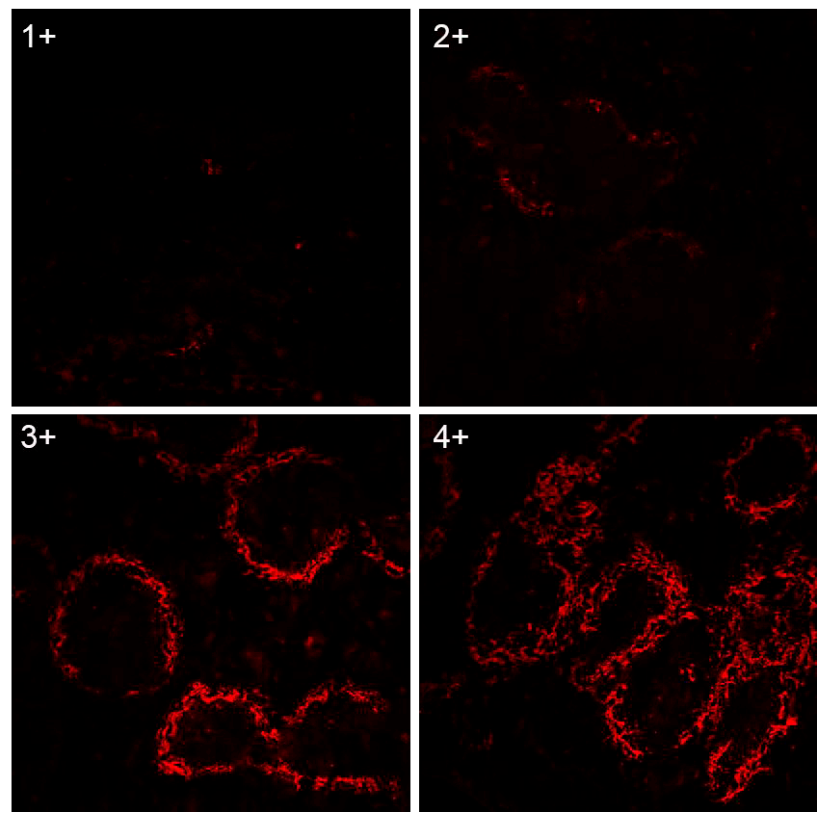

Figure 12. Representative examples of the amyloid grading in the spleen. Frozen spleen sections stained with Congo red are shown in fluorescence light. Amyloid appears as red materials and is graded from very thin focal deposits $(1+)$ to extensive amyloid deposits $(4+)$. 
Attempts were made to grade amyloid deposits by analyzing fluorescence intensity to obtain a quantitative method for grading in the spleen. However, this method only worked for amyloid grade $3+$ or $4+$, but for detection of small amyloid deposits (grade $1+$ and $2+$ ), this method is not sensitive enough. Therefore, the semi-quantitative method was used for grading of amyloid in polarized light. Amyloid grading was also performed in hFTAA stained spleen tissues (see below) using the same grading scale as for Congo red.

\section{LCOS}

LCO staining provides more sensitive and selective detection of amyloid compare to other conventional technique. By combining two LCOs with different fluorescence signatures and different modes of binding, the conformational differences in different amyloid polymorphs can be detected [82, 152]. In Paper III, hFTAA and qFTAA were used to stain different morphotypes of amyloid. Small immature amyloid deposits as well as mature amyloid could be detected using hFTAA, while qFTAA only binds to mature amyloid [82].

Analysis of hFTAA/qFTAA was made using an epifluorescence microscope and a hyperspectral camera. Samples were excited at $436 \mathrm{~nm}$ and emission spectra were collected between 460 and $700 \mathrm{~nm}$ through a long pass filter. In homogenous samples, spectra were collected from representative regions of interest and the ratio between the peaks at $500 \mathrm{~nm}$ (specific for qFTAA fluorescence) and $540 \mathrm{~nm}$ (specific for hFTAA fluorescence) was calculated for each spectrum. In tissue samples, where the distribution of spectral signatures is wide, a custom-made spectral correlation algorithm was used [153]. To facilitate this, reference spectra from sections stained with each LCO separately were determined. Similarities between the obtained spectrum and the reference spectra were compared using the algorithm and a correlation score was defined. Correlation score 1 means total overlap with the reference spectrum, while correlation score 0 means no overlap with the reference spectrum. The fraction of pixels that were $50 \%$ or more similar to qFTAA as compared to hFTAA were summed up and plotted as relative qFTAA contribution.

A mixture of qFTAA and hFTAA was used to stain both AEF and cryosections from spleen. In order to collect the reference spectra, spleen sections from mice sacrificed on day 23 were stained with qFTAA or hFTAA separately. 


\section{The delivery and uptake of liposomes}

Liposomes are artificial vesicles of spherical shape consisting of one or more phospholipid bilayers with a size ranging from $30 \mathrm{~nm}$ to several micrometers. Liposomes are not toxic and they are extensively used as carriers for numerous molecules such as drugs [154]. The lipid composition, surface charge, size and the number of lipid bilayers as well as the method of preparation have great impact on the properties of the liposome. For example large liposomes $(>400 \mathrm{~nm}$ ) are cleared more rapidly from the blood circulation than smaller [155]. By selecting different lipid composition, the surface charge of the liposomes can be altered, which might affect the liposome stability in the blood. Neutral liposomes are the most stable and bind the lowest amount of blood serum protein [156]. When liposomes interact with cells, their uptake and distribution occurs through different mechanisms depending on their size, charge and encapsulated molecule. For example liposomes of a diameter larger than $150 \mathrm{~nm}$ are phagocytosed by macrophages and Kupffer cells [157]. In Paper I and II, we used neutral multilayered liposomes containing phosphatidylcholine and cholesterol with the size ranging from $100 \mathrm{~nm}$ to 10 $\mu \mathrm{m}$. They were injected intravenously in mice in order to obtain efficient and fast uptake by e.g. macrophages. In accordance, using BODIPY-labelled liposomes, we showed that these liposomes were rapidly cleared from the circulation and taken up in spleen and liver. We also exposed the cell line J774.A1 to FITC encapsulated in liposomes and determined the co-localization with cellular organelles.

\section{Depletion of macrophages by liposomes encapsulated clodronate}

To deplete macrophages, the liposomal mediated macrophage suicide technique employing clodronate (dichloromethylene bisphosphonate) was used. This wellestablished method has been proven efficient and specific for depletion of macrophages in different tissues depending on the administration route [158]. Clodronate has a very short half-life, once it is released in the circulation, it is rapidly removed by the kidneys [159]. Free clodronate molecules cannot easily enter the cells and are therefore encapsulated in liposomes to be taken up by macrophages by endocytosis [160]. Intravenously injected liposomes with encapsulated clodronate are engulfed by macrophages and delivered to lysosomes. By lysosomal processes clodronate is released into the cytosol where it is converted into a non-hydrolysable ATP analog (AppCCl2p). The AppCCl2p binds to ATP/ADP translocase in the mitochondrial inner membrane and causes loss of the mitochondrial inner membrane integrity, which results in apoptosis $[161,162]$. 
The intravenous route of administration of liposomes encapsulated clodronate (CL) eliminate the macrophages in spleen, liver and bone marrow within $24 \mathrm{~h}$ [163]. The volume of $0.2 \mathrm{ml}$ of CL was injected which is the highest volume that is allowed to inject intravenously in mice and our most effective dose of liposomes in the current experimental design. This method was very efficient for depletion of RPMs and MZMs, but the depletion of MMZMs was incomplete, probably due to their localization in the inner part of the marginal sinus, which provide MMZMs an initial protection.

\section{Immunofluorescence}

Immunofluorescence is an antibody-based staining technique to visualize discrete components in tissues. To optimize the staining quality it is important to find a balance between preservation of the morphology through fixation and obtain high specificity of the antibody binding to the antigen [164]. In this thesis the tissue was cryopreserved. This technique preserves the antigenicity but has the disadvantage of poorer morphology and resolution at high magnification. The fixation is an important first step to immobilize the antigens. Formalin is the most widely used fixative and was used for detection of RPMs and MMZMs. However, for detection of MZMs in frozen spleen sections, ice cold acetone had to be used. The acetone is not an ideal fixative having strong dehydrating ability and resolves the membranes. On the other hand, for larger proteins or structures acetone is a good preservative. Regardless these disadvantages, acetone was found to give the best staining specificity for MZMs for SIGN-R1 antibody while for additional staining of MZMs, formalin was found to give the best staining for MARCO antibody. For detection of macrophages, monoclonal antibodies were used in Paper I and II. The monoclonal antibodies are highly specific for recognition of only one epitope and have low background noise. To determine the interaction and co-localization between amyloid and macrophages, Congo red staining was performed after completing incubation with the secondary antibody. In addition double immunostaining was performed in macrophages to analyze proliferation, using Ki67, and inflammasome activation by staining for the mature form of IL- $1 \beta$. To study the presence of IL- $1 \beta$ in spleen, the fixation was followed by treatment with Triton X-100 to obtain a more efficient penetration of the antibody.

Kidney sections were used as positive control for the IL-1 $\beta$ staining. As negative control kidney sections only stained with secondary antibody were used. The IL-1 $\beta$ antibody did not show any reactivity in acetone fixed kidneys but worked in paraformaldehyde or formalin fixed tissues. To detect co-staining between the MZM antibody SIGNR1, and IL-1 $\beta$ in MZMs, paraformaldehyde fixation was found to be the best compromise. 


\section{Confocal laser scanning microscopy}

Confocal laser scanning microscopy is an optical imaging technique, in which it is possible to obtain higher resolution and contrast than with conventional fluorescence microscopy. It enables to collect two-dimensional (2D) images at different depth in a sample (z-sections) and then construct images into a 3D image. The samples are exposed to a laser beam and the emitted light is collected and refocused through a pinhole aperture. The microscope was equipped with four lasers ( $405 \mathrm{~nm}, 488 \mathrm{~nm}, 555 \mathrm{~nm}$ and $639 \mathrm{~nm}$ ) to enable detection of multiple fluorophores within a sample. In fixed tissue samples, confocal microscopy was used to analyze presence of intracellular amyloid by determination of co-localization between splenic macrophages and amyloid by the use of Z-section. DAPI staining was used to stain the nuclei and localize individual cells. By rotating the 3D images, it was possible to detect the intracellular amyloid more easily.

\section{Quantification of splenic macrophages}

Quantification of splenic macrophages was performed on images obtained by confocal microscopy. Images of red pulp were captured at $63 \mathrm{x}$ magnification while images of marginal zones were captured at 20x magnification. All images were collected randomly. In Paper I, we showed that MZMs were depleted in the marginal zones with amyloid. Therefore in Paper II, images of the marginal zones were captured randomly but the quantification was only performed in regions with amyloid.

In order to prevent bias, all images were acquired under identical settings of the microscope and was used for further image processing. Image $\mathrm{J}$ software was used for quantification of macrophages and according to the threshold that was set, the labeled areas of macrophages were measured in each image and the mean value was calculated for each animal.

\section{Analysis of fibril morphology}

Transmission electron microscopy (TEM) was used to study the morphology of amyloid fibrils. The samples of interest were absorbed on formvar-coated copper grids, negatively stained with uranyl acetate, and viewed in a Jeol 1230 electron microscope. The morphology of the fibrils was determined by measurements of their length, width and periodicity of turns using Image J (Figure 13). To measure periodicity of turns, the distance between two pitches in twisted fibrils were measured and the average of 100 measurements was calculated. 


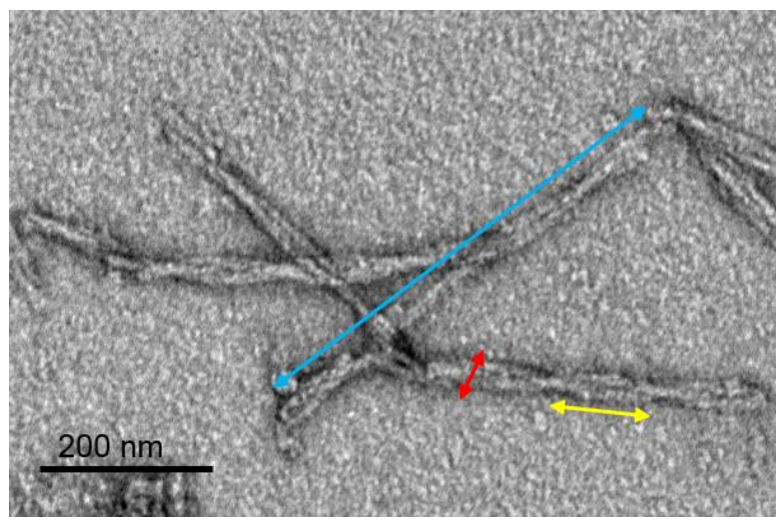

Figure 13. TEM micrograph of amyloid fibrils. The twisted fibrils usually have a distinct periodicity, which is illustrated by the yellow double headed arrow. The red double headed arrow shows the fibril width and the blue double headed arrow shows fibril length.

\section{Cell model}

Cell culture technique allows us to visualize cells and organelles in much higher resolution as compared to the tissue. Moreover, using cell culture the toxic effect of specific compound can be tested. The murine macrophage-like cell line J774A.1 was used in Paper II and III to study specific organelle uptake of liposomes as well as study the toxicity induced by AEF. This cell line is a well-established model systems in cell biology and immunology and can easily be maintained $[165,166]$. The cells grow fast and has been shown as an ideal model system for analysis of cellular processes like phagocytosis [167].

\section{Amyloid toxicity and cell viability}

It is recommended to use more than one method for the assessment of cellular death and toxicity. The analysis of membrane integrity is a common method to measure cellular viability and can be performed in different ways. One possible measurement is to quantify the leakage of cellular component over the plasma membrane into the culture medium. An example of this type of analysis is the lactate dehydrogenase (LDH) assay, which is a reliable colorimetric assay that is useful for detection of necrosis [168]. LDH is a cytosolic enzyme that catalyze the interconversion of lactate and pyruvate using reducing equivalents from $\mathrm{NAD}^{+} / \mathrm{NADH}+\mathrm{H}^{+}$. The reduction reaction is coupled to the formation of red formazan from tetrazolium salt and the level of formazan can be measured colorimetrically at $490 \mathrm{~nm}$. The level of formazan is proportional to the amount of LDH released from damaged cells into the medium [169]. 
Another useful alternative method to study cell death is the use of dyes able to differentiate between cells with intact and ruptured plasma membranes [170]. We used the combination of propidium iodide (PI) and Hoechst 33342. PI is a red-fluorescent nuclear stain that only penetrates cells with ruptured cell membrane, while normal cells with an intact plasma membrane exclude the dye. Thus, PI identifies necrotic cells. In contrast, Hoechst is a nuclear stain taken up by living cells. Hoechst positive cells were considered healthy if the nuclei were regular in shape, while cells with condensed or fragmented nuclei were considered apoptotic. Nuclei positive for both Hoechst and PI were considered necrotic [170]. The morphological changes during cell death was assessed by live cell imaging in an inverted confocal microscope. The percent of apoptotic and necrotic cells was calculated and compared to untreated controls.

\section{Stability assay of protein fibrils}

One common method to determine the stability of a protein is to study its denaturation with a chemical agent. Urea has the ability to interact with both polar and non-polar parts of proteins [171] and is therefore used to expose the non-polar core of the protein to the surface and thereby destabilize hydrophobic interactions [172]. This results in polarity changes of the solution. Nile red is a fluorescent dye with high sensitivity to the local polarity and high affinity to amyloid aggregates [173]. In a non-polar environment Nile red has an emission maximum at $620 \mathrm{~nm}$, which is shifted to an emission maximum above $650 \mathrm{~nm}$ in polar buffer [174]. In Paper III, the polarity of the fibril surface and the conformational stability of AEF1 and AEF2 were monitored by Nile red during exposure to increasing concentration of urea. Initially, Nile red interacts with the non-polar parts of AEF and when the urea concentration increases, the binding pocket for Nile red is unfolded releasing the dye to the surrounding media resulting in shift in emission wavelength. Samples were excited at $530 \mathrm{~nm}$ and emission spectra were collected between $550-800 \mathrm{~nm}$. 


\section{Results}

\section{Paper I}

\section{Depletion of spleen macrophages delays AA amyloid development: A study performed in the rapid mouse model of AA amyloidosis.}

In this paper we aimed to investigate both the role of splenic macrophages in amyloid formation and the amyloid toxicity to splenic macrophages in the mouse model of AA amyloidosis.

By immunofluorescence staining each kind of splenic macrophage was quantified and their location in relation to the amyloid deposits was determined. Our results indicate that the amyloid formation was accompanied by diverse reaction of the different macrophages. The area of RPMs staining was significantly increased due to the acute phase response and independent of amyloid formation. By using the proliferation marker Ki67, we showed that the observed increase is due to proliferation. At early stages of amyloid deposition, RPMs were not in contact with the amyloid but when the amyloid load increased these cells migrated towards the amyloid. The labeled area of MMZMs was not affected by the acute phase response or amyloid deposits. However, in the marginal zones with amyloid, MMZMs were intermingled with the deposits and minimal amyloid deposits were detected intracellularly. Interestingly, the labeled area of MZMs was increased in mice injected with $\mathrm{AgNO}_{3}$ alone. Also in inflamed mice exposed to AEF, the labeled area of MZMs was increased in areas lacking amyloid deposits. However, amyloid formation resulted in progressive reduction of MZMs and when the amyloid load was considerable, the MZMs were depleted. By studies in confocal microscopy of colocalization between each kind of macrophage and amyloid, we found intracellular amyloid in all types of macrophages suggesting that they were either involved in generation or degradation of amyloid.

To deplete splenic macrophages, mice were injected with CL, 2 days prior to amyloid induction. In all experimental groups that received $\mathrm{CL}$ alone or in combination with AEF and/or $\mathrm{AgNO}_{3}$, RPMs were totally depleted 2 days after CL injection; they started to reappear 6 days after CL injection and were reestablished after 18 days. MMZMs were not completely depleted 2 days after CL injection probably because being partially protected due to their localization in the inner region of the marginal zone. They 
reappeared 18 days after CL injection. MZMs were almost completely depleted 2 days after $\mathrm{CL}$ injection and did not reappear during the study period.

The number of mice that developed amyloid and the amyloid load was significantly decreased in mice that received CL. After 16 days of amyloid induction, all mice that received CL developed amyloid but the amyloid grade was lower as compared to mice that did not received CL. Since MZMs did not reappear, we conclude that they are not required for amyloid formation, however amyloid formation is delayed in the absence of these macrophages.

An unexpected observation of this study was that administration of CL per se resulted in amyloid development in all inflamed mice. This was an interesting finding because in mice that were treated with $\mathrm{AgNO}_{3}$ alone, amyloid was not detected indicating a role for the lipid membrane in the process.

In conclusion, Paper I shows that amyloid formation was very toxic to MZMs and increasing amyloid load caused progressive depletion of these macrophages. On the other hand, amyloid formation was not toxic to RPMs and MMZMs, although MMZMs were localized intermingled with the deposits. Depletion of macrophages, especially MZMs, before amyloid induction lead to delay in AA amyloid development. Under these conditions, MMZMs might be involved in the amyloid formation process while RPMs are probably involved in the amyloid degradation process. 


\section{Paper II}

\section{Lipid membranes accelerate amyloid formation in the mouse model of AA amyloidosis.}

In Paper I, we showed that multilayered liposomes encapsulated clodronate accelerate AA amyloid formation in inflamed mice. Therefore this study was aimed to investigate the amyloidogenic effect of lipid membranes and compare with the effect of AEF in terms of amyloid load and effect on splenic macrophages.

Mice were treated with multilayered liposomes containing PBS (Lipo) or AEF or the combination of $\mathrm{AEF} / \mathrm{Lipo}$ concurrent with $\mathrm{AgNO}_{3}$. In concordance with the findings in Paper I, liposomes accelerated amyloid formation but amyloid deposits induced by liposomes appeared later and were less pronounced than deposits induced by AEF. Interestingly, the combination of Lipo and AEF was less potent for amyloid induction than AEF alone.

Although we hypothesized that liposomes should accelerate amyloid formation by a mechanism different from AEF, the results obtained could not suggest any distinct differences between the amyloid deposited. Western blot analysis of spleen homogenates from inflamed mice treated with Lipo or AEF or the combination of AEF/Lipo revealed no differences in the size of the AA fragments. Moreover, regardless of induction method, amyloid formation was accompanied by depletion of MZMs, while RPMs and MMZMs appeared unaffected. IL-1 $\beta$ was produced mainly from RPMs in inflamed mice induced with AEF and/or liposomes and the expression of IL-1 $\beta$ was increased over a time.

Liposomes were rapidly cleared from the blood stream within 1 hour while spleen and liver uptake peaked after 3 hours and a complete clearance was found after 96 hours. In vitro studies using the J774A.1 cell line, showed that liposomes accumulated within lysosomes.

In conclusion, we showed that multilayered liposomes accelerate amyloid formation in the mouse model of AA amyloidosis but they were less powerful than AEF. Regardless of induction method, the amyloid formation was toxic to MZMs while RPMs and MMZMs remained unaffected. We could not define any particular mechanism by which liposomes induce amyloid formation. However, we speculate that accumulation of the liposomes within lysosomes could interfere with the SAA degradation process favoring fibril formation. Moreover, the interaction between lipid membranes and SAA might increase the local protein concentration and structural transformation of protein that results in enhancement of amyloid formation. 


\section{Paper III}

\section{Strain-like propagation and cell toxicity of murine AA amyloid polymorphs}

In model systems of other amyloid diseases, it has been shown that different polymorphs of amyloid can be propagated in vivo $[62,175]$. In our lab, we had access to two different AEFs, which gave us the opportunity to investigate if different polymorphs could be maintained in the mouse model of AA amyloidosis using conformation sensitive luminescent-conjugated oligothiophenes (LCOs) for the analysis.

AEF1 and AEF2 were extracted, using the same protocol, from liver of different pools of mice with AA amyloid. AEF1 had been stored for 21 years and originated from mice exposed to azocasein as inflammatory stimulation, while AEF2 was stored 4 years prior to the study and primarily raised in mice induced with $\mathrm{AgNO}_{3}$ and human $\mathrm{AA}$ amyloid extract

Electron microscopic characterization showed no significant differences in fibril length between AEF1 and AEF2. However AEF1 fibrils were significantly wider than AEF2 fibrils and had higher average periodicity. Analysis by western blot and mass spectrometry showed no major differences between AEF1 and AEF2. Although AEF1 showed higher conformational stability by Nile red binding, but denatured AEF1 and AEF2 presented highly similar Nile red fluorescence spectra. Characterization of the morphology by staining with a combination of hFTAA and qFTAA and analysis by fluorescence hyperspectral imaging revealed differences. Both AEF1 and AEF2 were composed of highly hFTAA positive material, but only AEF1 comprised qFTAA positive material. After injecting the respective AEF in inflamed mice, the pattern of LCO binding was analyzed in spleen deposits. The polymorphic appearance of AEF1 and AEF2 reflected the pattern of LCO binding to the respective AEF seed in vitro.

Cytotoxicity studies in the murine macrophage-like cell line J774.A1 showed that both AEF1 and AEF2 were toxic to the cells. However AEF2 was significantly more toxic than AEF1.

In conclusion, we showed that the two different AEF isolates displayed a significant difference in LCO spectra as well as fibrillar morphology and cytotoxicity. AEF1, able to bind qFTAA, represents a more mature morphology, while AEF2 is less mature and accordingly more toxic in cell culture experiments. The polymorph of amyloid aggregates was replicated in vivo in the mouse model of AA amyloidosis in a prion like mechanism. 


\section{Discussion}

\section{The relevance of mouse models in studies of AA amyloidosis}

Different sets of transgenic mouse models have been used in the investigation of AA disease. In transgenic mice expressing human IL-6 under the control of the mouse MT-I promoter (MT-I/hIL-6), the continuous IL-6 expression leads to increased circulating concentrations of SAA [176]. In these animals, amyloid typically develops at 5 months of age and the deposits are mostly detected in the perifollicular regions of the spleen. However, seeding with AA fibrils isolated from duck or goose foie gras, accelerates the development of the amyloid deposits to 3 weeks in this transgenic model [177]. In mice expressing doxycycline-inducible SAA, the SAA synthesis is increased independently of inflammation and AA amyloid develops after 5 weeks. In concordance with other described models, a single injection of amyloid extracts (AEF) results in amyloid development after 2 days [178]. This means that the overproduction of SAA, not the inflammation per se, is responsible for development of the disease. This is in agreement with the results from Paper I and II, where subcutaneous injection of $\mathrm{AgNO}_{3}$ triggered inflammation and AEF accelerated amyloid formation. We show that the SAA concentration is dependent on inflammation and is independent of amyloid formation or injection of liposomes. In contrast to the transgenic models, the inflammation inducible mouse model of AA amyloidosis that we used in our studies, has been widely used for investigation of AA amyloidosis [117, 119, 179]. This model mirror many aspects of human AA amyloidosis and may provide insights regarding the role of inflammatory cytokines in stimulating the production of SAA as well as the role of macrophages in generation of AA and proteolysis of SAA. Human AA amyloidosis typically develops after many years of chronic inflammatory disease and not all patients will be affected. In the mouse model, AA deposition is accelerated by administration of different kinds of seed, including AEF, concurrent with inflammatory stimulation. Therefore, it is interesting to speculate that AA deposition in human also may be triggered upon exposure to some kind of seed. 


\section{The role of macrophages in inflammation}

The role of SAA during inflammation and the relationship between SAA concentration and amyloid deposition is still unclear [179, 180]. It has been suggested that SAA concentration is reduced during amyloid formation due to the deposition of circulating SAA in the tissue and therefore the patient with higher amyloid load may show lower SAA concentration [181]. However in our study we could not correlate the amount of SAA to the amyloid load (Paper II).

Lower SAA concentrations were found in the groups of mice with depleted macrophages, compare to the corresponding control (Paper I). This is probably due to the elimination of RPMs, which results in lower concentration of proinflammatory cytokines such as TNF- $\alpha$ and IL-6, both important for SAA elevation during the acute phase response [135]. Moreover, it has been described that SAA itself has the ability to induce production of proinflammatory cytokines such as TNF- $\alpha$, IL- 8 and IL- $1 \beta$ and may thereby amplify the inflammatory process $[182,183]$.

IL-1 $\beta$ was detected in the red pulp after 1 hour in inflamed mice injected with AEF and/or liposomes and increased over time (Paper II). Interestingly, in mice that received only $\mathrm{AgNO}_{3}$, no IL-1 $\beta$ expression was detected, although the SAA level was high. Therefore, we speculate that AEF per se might activate the inflammasome. This is in accordance with the finding that oligomers of islet amyloid polypeptide activate the NLRP3 inflammasome and produce mature IL-1 $\beta$ [184].

\section{Macrophages in AA amyloidogenesis}

Monocytes isolated form healthy individuals has been shown to degrade SAA completely, while monocytes from patients with amyloidosis instead produce SAA intermediates [185]. SAA bound to HDL is taken up by endocytosis and the degradation can therefore take place in lysosomes [186]. Among several different lysosomal cathepsins, cathepsin $\mathrm{B}$ has been shown to produce the amyloidogenic fragment of 76 residues [187]. We also found that the predominant AA fragment in spleen corresponded to the 76 amino acid residue (Paper III). Recently an in vitro study of J774.A1 cells incubated with recombinant SAA1 and HDL showed that accumulation of intralysosomal amyloid eventually caused lysosomal membrane permeabilization and cell death with release of the AA amyloid deposits extracellularly [188]. Moreover they showed that the amyloid could only be detected if the incubation time was more than 20 hours, which indicates that the internalization of SAA into the cells should be long enough to exceed their proteolytic capacity [188]. A study performed in cell cultures of mouse peritoneal macrophages indicates that the endocytosis of SAA leads to incomplete degradation of SAA and cleavage of SAA into AA fragments followed by extracellular deposition of 
amyloid [189]. We showed that amyloid formation was very toxic to MZMs (Paper I and II). In accordance with the cell models described above, we speculate that the overproduction of SAA during acute inflammation exceed the lysosomal proteases capacity of MZMs and results in incomplete lysosomal degradation of SAA. In presence of AEF the amyloid propagation can occur, which eventually results in cell death and release of extracellular amyloid. We could not determine if SAA proteolysis was intracellular or extracellular, but since we detected intracellular amyloid in MZMs (Paper I), the amyloid is at least initially intracellular. The impact of MZMs in amyloid formation is, however, challenged by the macrophage depletion experiments (Paper I), since no recovery of these macrophages is detected. This indicates that MZMs are important but not crucial for formation of amyloid.

The exact role of RPMs in amyloidosis in not clear. Several studies indicate that the proliferation of resident macrophages is increased during inflammatory conditions [190193]. In Paper I and II, we showed that RPMs proliferate in response to $\mathrm{AgNO}_{3}$ and probably their proliferation is independent of amyloid. After depletion of macrophages with clodronate, RPMs are initially completely depleted but is then the first cell type to reappear and shows approximately $40 \%$ recovery 6 days after CL administration. RPMs are therefore possible candidates that may have a role in amyloid formation. On the other hand, at early time points and low amyloid load there is a distinct distance between the amyloid deposits and the RPMs. In studies of the clearance of amyloid in mouse model of AA amyloidosis, F4/80 positive macrophages colocalize with amyloid A during amyloid resolution [117]. Thus, we speculate that RPMs are involved in the amyloid degradation rather than amyloid formation due to their migration towards amyloid at the later stage.

MMZMs form a continuous ring-like structure in the inner part of the marginal zone, and contained minimal intracellularly amyloid deposits (Paper I). Interestingly, after 16 days in the presence of extensive amount of amyloid, MMZMs have partially migrated into the white pulp. MMZMs are highly phagocytic and able to transfer the antigens to splenic dendritic cells leading to activation of T-cell responses [194]. In addition, MMZMs can serve as antigen presenting cells stimulating secretion of $\operatorname{IgM}$ and $\operatorname{IgG}$ antibodies against protein AA [195]. Therefore the activation of B cells against amyloid might be a reason for the MMZMs to migrate toward the white pulp.

After CL injection, low number of MMZMs are still present in the inner part of the marginal zone (Paper I). It has been previously shown that the phagocytic cells distant from the circulation have lower access to blood born particles such as clodronate containing liposomes [196]. MMZMs had not recovered 6 days after CL injection, but since a low number of MMZMs remained after depletion they are possible candidates to have a role in amyloid formation. After 16 day over $80 \%$ of the MMZMs had recovered and amyloid was detected in spleen of all mice but with lower amyloid grade as compared to mice with normal number of macrophages. A study in the huIL-6 transgenic mice that 
were injected with labeled AEF 24 hours after clodronate containing liposomes injection, indicates that the distribution of AEF in spleen and liver is not affected by macrophage depletion [196]. However they only showed overall uptake of AEF in the spleen without determining the distribution in macrophages. Therefore it is possible that in the absence of splenic macrophages, AEF is accumulated extracellularly in spleen.

In summary, macrophages have a central and complex role in inflammation and AA amyloidosis. By production of proinflammatory cytokines, they maintain the inflammation and simultaneously by uptake of SAA-HDL contribute to degradation of SAA. Malfunction or overload during the degradation might lead to accumulation of amyloidogenic peptides that risk to form a nucleus. In the presence of e.g., AEF, propagation of the amyloid formation might inevitably take place.

\section{The role of lipid membranes in amyloidogenesis}

Interaction between membranes and amyloidogenic proteins is of great interest for protein folding and aggregation, and has been shown to be involved in the pathology of amyloidogenic proteins such as A $\beta, \alpha$-synuclein, and IAPP [197-199]. Several studies with the $A \beta$ peptide indicate that the toxicity is induced via interaction of the peptide with lipid membranes, although the interaction is not characterized in detail [200, 201].

Interestingly, in our studies we found AA amyloid deposits in mice treated with $\mathrm{AgNO}_{3}$ and liposomes (Paper I and II). Since liposomes could not have a seeding effect, the mechanism of amyloid formation must differ from that of AEF.

Although in vitro studies indicate that the proteolytic cleavage of SAA results in AA amyloid deposition [186], many aspects of AA amyloid deposition in vivo are still unclear. For instance, it is not yet explored, whether the precursor protein of AA fragments is the lipid-free SAA, the HDL-bound SAA, or the misfolded $\beta$-sheet-rich aggregated SAA. It has been shown in vitro that addition of HDL or lipid particles stabilizes the SAA in the $\alpha$-helical conformation and consequently protects it from fibrillation [202]. However, if the HDL bound SAA is internalized into cells, the protective effect of HDL is inhibited [188]. Moreover SAA-HDL forms marginally stable $\alpha$-helices at $37{ }^{\circ} \mathrm{C}$ near to physiological condition, which differs from the stable $\alpha$-helical structure. This marginally stable $\alpha$-helices promote the intermolecular interaction and leads to conversion from $\alpha$ helices to $\beta$-sheets in amyloid [202]. The same mechanism has been described for $A \beta$ peptide at the lipid surface $[203,204]$. Therefore we speculate that, when SAA-HDL is internalized into the macrophages, the HDL is released from SAA and in the presence of liposomes, SAA forms the marginally stable $\alpha$-helices, which facilitate the formation of $\beta$-sheet and consequently results in formation of amyloid.

In vitro studies has shown that lysosomes are the initial sites of AA fibril formation [84, 160]. Moreover, for many amyloid precursor proteins such as SAA, transthyretin, Ig light 
chain and $\mathrm{A} \beta$ peptide, the acidic $\mathrm{pH}$ of the lysosomal compartment is important for amyloid fibril formation [205, 206]. An in vitro study of lipid free SAA indicates that at $\mathrm{pH} 3.5-4.5$ stable oligomers highly resistance to proteolysis are formed and as they escape from lysosomal degradation they accumulate in the lysosomes [207]. Following the fluorescent liposomes in vitro, we showed that liposomes are phagocytosed by macrophages and co-localize with lysosomes, where SAA is also internalized. Thus, addition of liposomes can facilitate the conversion of these oligomers to form intracellular amyloid, which probably results in cell death.

Taken together, we showed for the first time that lipid membranes have amyloidogenic effect in the mouse model of AA amyloidosis. Thus, liposomes offer a new model system for studies of AA amyloid formation in vivo.

\section{AA amyloid polymorphs and templating}

The heterogeneous amyloid morphotypes has been observed in different amyloid forming proteins, such as $\mathrm{A} \beta$, transthyretin and AA amyloid [105, 175, 208]. In amyloid deposits, protein AA consists of a mixture of peptides of different length and it has been shown that different clinical and histological appearances of the disease are reflected in the length of the AA amyloid fibrils [209]. The seed dependent templating has been shown in A $\beta$ amyloid where the $A \beta$ morphotype is transmitted to transgenic mice overexpressing the $A \beta$ precursor protein [210]. The same phenomenon has been observed in a study of transmission using transgenic mice overexpressing $\operatorname{PrP}$ [211]. In experimental inflammatory-induced murine AA amyloidosis, administration of amyloid fibril extract from the same or different animal species as well as amyloid like fibrils will shorten the time for onset of amyloid development. This indicates that AA amyloidosis could be transmissible and that the transmission mechanism is similar to that of the prion disease $[125,212-214]$.

In Paper III, we used two different murine amyloid extracts named AEF1 and AEF2, originated from two different sources, of different age, as well as concentration. The combination of qFTAA and hFTAA was used to determine the conformational differences. Both AEF1 and AEF2 were highly positive for hFTAA, which detects immature amyloid deposits as well as mature. However, only AEF1 was positive for qFTAA, which previously has been shown to bind mature amyloid with rigid and ordered structure $[82,83,215]$. Interestingly, the fibrillar morphology, of AEF1 was significantly different from a grid of fresh AEF1, prepared 21 years earlier, as studied by TEM (Paper III). This indicates that rearrangement of the amyloid fibrils had occurred during storage. Similarly, in a transgenic mouse model of Alzheimer's disease, the conformational properties of amyloid changed as the animal aged $[83,216]$. Therefore we assume that AEF1 prepared from amyloid laden liver collected 21-28 days post amyloid induction 
contain more mature amyloid than AEF2 prepared from liver collected 16 days post induction. Thus, it is likely that the age differences at preparation and after storage between AEF1 and AEF2, used in Paper III, is a factor that determine the different conformational structures. Moreover, it has been reported that polymorphic differences between murine and human AA amyloid exist [217]. Since the origin of AEF1 and AEF2 is from mouse and human, respectively, the conformational differences could also be due to the differences in their origins. Furthermore, the spectral characteristics of the LCO fluorescence was similar even when different concentrations of AEF1 or AEF2 were stained with LCOs. This indicate that the binding of amyloid AA to LCOs is not concentration dependent.

The LCO staining showed that the conformational properties of AEF1 and AEF2 was retained in the respective spleen tissues (Paper III). This indicates a templating mechanism where the conformation of the seed is transmitted in a prion-like manner. It has been shown that more mature $A \beta$ fibrils are less toxic than the immature fibrils in a Drosophila model of Alzheimer's disease [218]. Our results from cell culture studies in Paper III indicate that AEF1 with more rigid structure and more mature fibrils induced less toxicity when compared to AEF2. The corresponding comparison of toxicity is however more challenging to do in tissue. In Paper I and II, AEF2 was used as seed in the mouse experiments and we found that the MZMs were very sensitive to amyloid formation, and increasing amyloid load caused progressive depletion of this population of macrophage. We could not elucidate the mechanism of cytotoxicity, however, detection of intracellular amyloid deposits indicate an intracellular process. Since MZMs were also progressively depleted after amyloid induction with liposomes, we conclude that amyloid formation induces toxicity to MZMs regardless of the method of amyloid induction. In Paper III, the hFTAA positivity was detected in amyloid deposits induced by both AEF1 and AEF2. However, the qFTAA positive amyloid deposits were not detected until 14 days after amyloid induction with AEF1 and at this time point most MZMs were already depleted. These results are interpreted as that formation of amyloid with immature conformation is toxic to MZMs in vivo.

Taken together, we showed for the first time that the polymorph dependent templating is not only a characteristic for prion strains, but also occurs in AA amyloidosis. Amyloid toxicity is related to the amyloid polymorph. 


\section{Conclusions}

From the findings presented in this thesis the following conclusions can be drawn:

- In the rapid AA amyloid mouse model, splenic macrophages contribute to the maintenance of inflammation. Amyloid or amyloid formation has an important impact on the distribution of splenic macrophages. Regardless of induction method used in inflamed mice, amyloid formation is highly toxic to MZMs, while RPMs and MMZMs appeare insensitive to amyloid. RPMs migrate towards the amyloid when amyloid is extended, which indicate that RPMs may be involved in amyloid degradation.

- Depletion of macrophages, especially MZMs, before amyloid induction results in delayed amyloid development. MMZMs are re-established before MZMs and may therefore have a role in amyloid formation in absence of MZMs.

- Lipid membranes induce amyloid formation in inflamed mice. The amyloidogenic effect of lipid membranes is weaker as compared to AEF. Intravenously injected liposomes are rapidly cleared by spleen and liver and co-localized with lysosomes. The accumulation of liposomes in lysosomes may interfere with the SAA degradation process and promote amyloid formation.

- Characterization of two AEF preparations revealed different ultrastructure and LCOsensitive conformation. The structural properties of the amyloid fibril polymorphs are linked to their cytotoxicity.

- Two different AEF template their respective polymorphs on the host when used to induce amyloid formation in inflamed mice. This indicate that strain-like propagation occurs in the experimental mouse AA amyloidosis model. 


\section{References}

1. Dobson, C.M., Protein folding and misfolding. Nature, 2003. 426: p. 884-90.

2. Adamcik, J. and R. Mezzenga, Amyloid Polymorphism in the Protein Folding and Aggregation Energy Landscape. Angew Chem Int Ed Engl, 2018. 57: p. 8370-8382.

3. Song, J., Why do proteins aggregate? Intrinsically insoluble proteins"and dark mediators" revealed by studies on insoluble proteins'solubilized in pure water. F1000Res, 2013. 2: p. 94.

4. Anfinsen, C.B., Principles that govern the folding of protein chains. Science, 1973. 181: p. $223-30$.

5. Westermark, G.T., M. Fandrich, and P. Westermark, AA amyloidosis: pathogenesis and targeted therapy. Annu Rev Pathol, 2015. 10: p. 321-44.

6. Westermark, G.T. and P. Westermark, Serum amyloid A and protein AA: molecular mechanisms of a transmissible amyloidosis. FEBS Lett, 2009. 583: p. 2685-90.

7. Virchow, R., Ueber eine im Gehirn und Rückenmark des Menschen aufgefundene Substanz mit der chemischen Reaction der Cellulose. Archiv für pathologische Anatomie und Physiologie und für klinische Medicin, 1854. 6: p. 135-138.

8. Friedreich, N. and A. Kekulé, Zur Amyloidfrage. Archiv für Pathologische Anatomie und Physiologie und für Klinische Medicin, 1859. 16: p. 50-65.

9. Puchtler, H., F. Sweat, and M. Levine, On the Binding of Congo Red by Amyloid. Journal of Histochemistry \& Cytochemistry, 1962. 10: p. 355-364.

10. Missmahl, H.P. and M. Hartwig, Polarisationsoptische Untersuchungen an der Amyloidsubstanz. Virchows Archiv fur Pathologische Anatomie und Physiologie und fur Klinische Medizin, 1953. 324: p. 489-508.

11. Cohen, A.S. and E. Calkins, Electron Microscopic Observations on a Fibrous Component in Amyloid of Diverse Origins. Nature, 1959. 183: p. 1202-1203.

12. Eanes, E.D. and G.G. Glenner, X-ray diffraction studies on amyloid filaments. J Histochem Cytochem, 1968. 16: p. 673-7.

13. Sipe, J.D., M.D. Benson, J.N. Buxbaum, S.-i. Ikeda, G. Merlini, M.J.M. Saraiva, and P. Westermark, Nomenclature 2014: Amyloid fibril proteins and clinical classification of the amyloidosis. Amyloid, 2014. 21: p. 221-224. 
14. Kisilevsky, R., The relation of proteoglycans, serum amyloid $P$ and Apo E to amyloidosis current status, 2000. Amyloid-International Journal of Experimental and Clinical Investigation, 2000. 7: p. 23-25.

15. Pepys, M.B., M.L. Baltz, F.C. de Beer, R.F. Dyck, S. Holford, S.M. Breathnach, M.M. Black, C.R. Tribe, D.J. Evans, and A. Feinstein, Biology of serum amyloid P component. Ann N Y Acad Sci, 1982. 389: p. 286-98.

16. Ancsin, J.B., Amyloidogenesis: historical and modern observations point to heparan sulfate proteoglycans as a major culprit. Amyloid, 2003. 10: p. 67-79.

17. Pepys, M.B., Amyloidosis. Annual Review of Medicine, 2006. 57: p. 223-241.

18. Benson, M.D., J.N. Buxbaum, D.S. Eisenberg, G. Merlini, M.J.M. Saraiva, Y. Sekijima, J.D. Sipe, and P. Westermark, Amyloid nomenclature 2018: recommendations by the International Society of Amyloidosis (ISA) nomenclature committee. Amyloid, 2018. 25: p. 215-219.

19. Perticaroli, S., J.D. Nickels, G. Ehlers, H. O'Neill, Q. Zhang, and A.P. Sokolov, Secondary structure and rigidity in model proteins. Soft Matter, 2013. 9: p. 9548-56.

20. Nelson, R., M.R. Sawaya, M. Balbirnie, A.O. Madsen, C. Riekel, R. Grothe, and D. Eisenberg, Structure of the cross-beta spine of amyloid-like fibrils. Nature, 2005. 435: p. $773-8$.

21. Eisenberg, D. and M. Jucker, The amyloid state of proteins in human diseases. Cell, 2012. 148: p. 1188-203.

22. Serpell, L.C., M. Sunde, M.D. Benson, G.A. Tennent, M.B. Pepys, and P.E. Fraser, The protofilament substructure of amyloid fibrils. J Mol Biol, 2000. 300: p. 1033-9.

23. Knowles, T.P., M. Vendruscolo, and C.M. Dobson, The amyloid state and its association with protein misfolding diseases. Nat Rev Mol Cell Biol, 2014. 15: p. 384-96.

24. Kim, Y.E., M.S. Hipp, A. Bracher, M. Hayer-Hartl, and F.U. Hartl, Molecular chaperone functions in protein folding and proteostasis. Annu Rev Biochem, 2013. 82: p. 323-55.

25. Doyle, S.M., O. Genest, and S. Wickner, Protein rescue from aggregates by powerful molecular chaperone machines. Nat Rev Mol Cell Biol, 2013. 14: p. 617-29.

26. Selkoe, D.J., Folding proteins in fatal ways. Nature, 2003. 426: p. 900-4.

27. Chiti, F. and C.M. Dobson, Protein Misfolding, Amyloid Formation, and Human Disease: A Summary of Progress Over the Last Decade. Annu Rev Biochem, 2017. 86: p. 27-68. 
28. Nick Pace, C., J.M. Scholtz, and G.R. Grimsley, Forces stabilizing proteins. FEBS Lett, 2014. 588: p. 2177-84.

29. Onuchic, J.N., Z. Luthey-Schulten, and P.G. Wolynes, Theory of protein folding: the energy landscape perspective. Annu Rev Phys Chem, 1997. 48: p. 545-600.

30. Balchin, D., M. Hayer-Hartl, and F.U. Hartl, In vivo aspects of protein folding and quality control. Science, 2016. 353: p. 4354.

31. Morales, R., I. Moreno-Gonzalez, and C. Soto, Cross-seeding of misfolded proteins: implications for etiology and pathogenesis of protein misfolding diseases. PLoS Pathog, 2013. 9: p. e1003537.

32. Cohen, S.I., M. Vendruscolo, C.M. Dobson, and T.P. Knowles, From macroscopic measurements to microscopic mechanisms of protein aggregation. J Mol Biol, 2012. 421: p. $160-71$.

33. Arosio, P., T.P. Knowles, and S. Linse, On the lag phase in amyloid fibril formation. Phys Chem Chem Phys, 2015. 17: p. 7606-18.

34. Westermark, G.T., M. Fandrich, K. Lundmark, and P. Westermark, Noncerebral Amyloidoses: Aspects on Seeding, Cross-Seeding, and Transmission. Cold Spring Harb Perspect Med, 2018. 8: p. a024323.

35. Tornquist, M., T.C.T. Michaels, K. Sanagavarapu, X. Yang, G. Meisl, S.I.A. Cohen, T.P.J. Knowles, and S. Linse, Secondary nucleation in amyloid formation. Chem Commun (Camb), 2018. 54: p. 8667-8684.

36. Cohen, S.I.A., S. Linse, L.M. Luheshi, E. Hellstrand, D.A. White, L. Rajah, D.E. Otzen, M. Vendruscolo, C.M. Dobson, and T.P.J. Knowles, Proliferation of amyloid- 42 aggregates occurs through a secondary nucleation mechanism. Proceedings of the National Academy of Sciences, 2013. 110: p. 9758-9763.

37. Ruschak, A.M. and A.D. Miranker, Fiber-dependent amyloid formation as catalysis of an existing reaction pathway. Proceedings of the National Academy of Sciences, 2007. 104: p. 12341-12346.

38. De Genst, E., A. Messer, and C.M. Dobson, Antibodies and protein misfolding: From structural research tools to therapeutic strategies. Biochimica et Biophysica Acta (BBA) - Proteins and Proteomics, 2014. 1844: p. 1907-1919.

39. Hasegawa, K., I. Yamaguchi, S. Omata, F. Gejyo, and H. Naiki, Interaction between A beta(1-42) and $A$ beta(1-40) in Alzheimer's beta-amyloid fibril formation in vitro. Biochemistry, 1999. 38: p. 15514-21. 
40. Harper, J.D., C.M. Lieber, and P.T. Lansbury, Jr., Atomic force microscopic imaging of seeded fibril formation and fibril branching by the Alzheimer's disease amyloid-beta protein. Chem Biol, 1997. 4: p. 951-9.

41. Jarrett, J.T. and P.T. Lansbury, Jr., Seeding öne-dimensional crystallization"of amyloid: a pathogenic mechanism in Alzheimer's disease and scrapie? Cell, 1993. 73: p. 1055-8.

42. O'Nuallain, B., A.D. Williams, P. Westermark, and R. Wetzel, Seeding specificity in amyloid growth induced by heterologous fibrils. J Biol Chem, 2004. 279: p. 17490-9.

43. Fernández-Borges, N., H. Eraña, S.R. Elezgarai, C. Harrathi, M. Gayosso, and J. Castilla, Infectivity versus Seeding in Neurodegenerative Diseases Sharing a Prion-Like Mechanism. International Journal of Cell Biology, 2013. 2013: p. 583498.

44. Soto, C. and G.P. Saborio, Prions: disease propagation and disease therapy by conformational transmission. Trends Mol Med, 2001. 7: p. 109-14.

45. Soto, C., L. Estrada, and J. Castilla, Amyloids, prions and the inherent infectious nature of misfolded protein aggregates. Trends Biochem Sci, 2006. 31: p. 150-5.

46. Soto, C., Transmissible proteins: expanding the prion heresy. Cell, 2012. 149: p. 968-77.

47. Wei, G., Z. Su, N.P. Reynolds, P. Arosio, I.W. Hamley, E. Gazit, and R. Mezzenga, Selfassembling peptide and protein amyloids: from structure to tailored function in nanotechnology. Chemical Society Reviews, 2017. 46: p. 4661-4708.

48. Siontorou, C., G.-P. Nikoleli, D. Nikolelis, and S. Karapetis, Artificial Lipid Membranes: Past, Present, and Future. Membranes, 2017. 7: p. 38.

49. Terakawa, M.S., H. Yagi, M. Adachi, Y.H. Lee, and Y. Goto, Small liposomes accelerate the fibrillation of amyloid beta (1-40). J Biol Chem, 2015. 290: p. 815-26.

50. Smith, P.E.S., J.R. Brender, and A. Ramamoorthy, Induction of Negative Curvature as a Mechanism of Cell Toxicity by Amyloidogenic Peptides: The Case of Islet Amyloid Polypeptide. Journal of the American Chemical Society, 2009. 131: p. 4470-4478.

51. Armstrong, C.L., E. Sandqvist, and M.C. Rheinstadter, Protein-protein interactions in membranes. Protein Pept Lett, 2011. 18: p. 344-53.

52. Galvagnion, C., A.K. Buell, G. Meisl, T.C. Michaels, M. Vendruscolo, T.P. Knowles, and C.M. Dobson, Lipid vesicles trigger alpha-synuclein aggregation by stimulating primary nucleation. Nat Chem Biol, 2015. 11: p. 229-34.

53. Fusco, G., A. De Simone, T. Gopinath, V. Vostrikov, M. Vendruscolo, C.M. Dobson, and G. Veglia, Direct observation of the three regions in $\alpha$-synuclein that determine its membrane-bound behaviour. Nature Communications, 2014. 5: p. 3827. 
54. Gorbenko, G.P. and P.K. Kinnunen, The role of lipid-protein interactions in amyloid-type protein fibril formation. Chem Phys Lipids, 2006. 141: p. 72-82.

55. Eliezer, D., E. Kutluay, R. Bussell, Jr., and G. Browne, Conformational properties of alpha-synuclein in its free and lipid-associated states. J Mol Biol, 2001. 307: p. 1061-73.

56. Accardo, A., V. Shalabaeva, M. Cotte, M. Burghammer, R. Krahne, C. Riekel, and S. Dante, Amyloid $\beta$ Peptide Conformational Changes in the Presence of a Lipid Membrane System. Langmuir, 2014. 30: p. 3191-3198.

57. Song, H., S. Ritz, W. Knoll, and E.-K. Sinner, Conformation and topology of amyloid $\beta$ protein adsorbed on a tethered artificial membrane probed by surface plasmon fieldenhanced fluorescence spectroscopy. Journal of Structural Biology, 2009. 168: p. 117124.

58. Vestergaard, M.d., T. Hamada, and M. Takagi, Using model membranes for the study of amyloid beta:lipid interactions and neurotoxicity. Biotechnology and Bioengineering, 2008. 99: p. 753-763.

59. Seubert, P., T. Oltersdorf, M.G. Lee, R. Barbour, C. Blomquist, D.L. Davis, K. Bryant, L.C. Fritz, D. Galasko, L.J. Thal, and et al., Secretion of beta-amyloid precursor protein cleaved at the amino terminus of the beta-amyloid peptide. Nature, 1993. 361: p. 260-3.

60. Bokvist, M. and G. Gröbner, Misfolding of Amyloidogenic Proteins at Membrane Surfaces: The Impact of Macromolecular Crowding. Journal of the American Chemical Society, 2007. 129: p. 14848-14849.

61. Fändrich, M., J. Meinhardt, and N. Grigorieff, Structural polymorphism of Alzheimer A and other amyloid fibrils. Prion, 2014. 3: p. 89-93.

62. Annamalai, K., K.-H. Gührs, R. Koehler, M. Schmidt, H. Michel, C. Loos, P.M. Gaffney, C.J. Sigurdson, U. Hegenbart, S. Schönland, and M. Fändrich, Polymorphism of Amyloid Fibrils In Vivo. Angewandte Chemie International Edition, 2016. 55: p. 4822-4825.

63. Klement, K., K. Wieligmann, J. Meinhardt, P. Hortschansky, W. Richter, and M. Fandrich, Effect of different salt ions on the propensity of aggregation and on the structure of Alzheimer's abeta(1-40) amyloid fibrils. J Mol Biol, 2007. 373: p. 1321-33.

64. Petkova, A.T., R.D. Leapman, Z. Guo, W.M. Yau, M.P. Mattson, and R. Tycko, Selfpropagating, molecular-level polymorphism in Alzheimer's beta-amyloid fibrils. Science, 2005. 307: p. 262-5.

65. Collinge, J. and A.R. Clarke, A general model of prion strains and their pathogenicity. Science, 2007. 318: p. 930-6. 
66. Cohen, F.E. and S.B. Prusiner, Pathologic conformations of prion proteins. Annu Rev Biochem, 1998. 67: p. 793-819.

67. Aguzzi, A., M. Heikenwalder, and M. Polymenidou, Insights into prion strains and neurotoxicity. Nat Rev Mol Cell Biol, 2007. 8: p. 552-61.

68. Kroemer, G., L. Galluzzi, P. Vandenabeele, J. Abrams, E.S. Alnemri, E.H. Baehrecke, M.V. Blagosklonny, W.S. El-Deiry, P. Golstein, D.R. Green, M. Hengartner, R.A. Knight, S. Kumar, S.A. Lipton, W. Malorni, G. Nuñez, M.E. Peter, J. Tschopp, J. Yuan, M. Piacentini, B. Zhivotovsky, and G. Melino, Classification of cell death: recommendations of the Nomenclature Committee on Cell Death 2009. Cell Death \& Differentiation, 2008. 16: p. 3-11.

69. D'Arcy, M.S., Cell death: a review of the major forms of apoptosis, necrosis and autophagy. Cell Biology International, 2019. 43: p. 582-592.

70. Escobar, M.L., O.M. Echeverría, and G.H. Vázquez-Nin, Necrosis as Programmed Cell Death. 2015.

71. Elmore, S., Apoptosis: A Review of Programmed Cell Death. Toxicologic Pathology, 2016. 35: p. 495-516.

72. Silva, M.T., Secondary necrosis: The natural outcome of the complete apoptotic program. FEBS Letters, 2010. 584: p. 4491-4499.

73. Haass, C. and D.J. Selkoe, Soluble protein oligomers in neurodegeneration: lessons from the Alzheimer's amyloid beta-peptide. Nat Rev Mol Cell Biol, 2007. 8: p. 101-12.

74. Hebda, J.A. and A.D. Miranker, The interplay of catalysis and toxicity by amyloid intermediates on lipid bilayers: insights from type II diabetes. Annu Rev Biophys, 2009. 38: p. 125-52.

75. Modler, A.J., K. Gast, G. Lutsch, and G. Damaschun, Assembly of amyloid protofibrils via critical oligomers--a novel pathway of amyloid formation. J Mol Biol, 2003. 325: p. 135-48.

76. Stroud, J.C., C. Liu, P.K. Teng, and D. Eisenberg, Toxic fibrillar oligomers of amyloidbeta have cross-beta structure. Proc Natl Acad Sci U S A, 2012. 109: p. 7717-22.

77. Kandel, N., T. Zheng, Q. Huo, and S.A. Tatulian, Membrane Binding and Pore Formation by a Cytotoxic Fragment of Amyloid $\beta$ Peptide. The Journal of Physical Chemistry B, 2017. 121: p. 10293-10305.

78. Taneja, V., M. Verma, and A. Vats, Toxic species in amyloid disorders: Oligomers or mature fibrils. Annals of Indian Academy of Neurology, 2015. 18: p. 138. 
79. Fandrich, M., Oligomeric intermediates in amyloid formation: structure determination and mechanisms of toxicity. J Mol Biol, 2012. 421: p. 427-40.

80. Yakupova, Elmira I., Liya G. Bobyleva, Ivan M. Vikhlyantsev, and Alexander G. Bobylev, Congo Red and amyloids: history and relationship. Bioscience Reports, 2019. 39: p. BSR20181415.

81. Glenner, G.G., E.D. Eanes, and D.L. Page, The relation of the properties of Congo redstained amyloid fibrils to the -conformation. J Histochem Cytochem, 1972. 20: p. 821-6.

82. Klingstedt, T., A. Åslund, R.A. Simon, L.B.G. Johansson, J.J. Mason, S. Nyström, P. Hammarström, and K.P.R. Nilsson, Synthesis of a library of oligothiophenes and their utilization as fluorescent ligands for spectral assignment of protein aggregates. Organic \& Biomolecular Chemistry, 2011. 9: p. 8356-70.

83. Nyström, S., K.M. Psonka-Antonczyk, P.G. Ellingsen, L.B.G. Johansson, N. Reitan, S. Handrick, S. Prokop, F.L. Heppner, B.M. Wegenast-Braun, M. Jucker, M. Lindgren, B.T. Stokke, P. Hammarström, and K.P.R. Nilsson, Evidence for Age-Dependent in Vivo Conformational Rearrangement within A A Amyloid Deposits. ACS Chemical Biology, 2013. 8: p. 1128-1133.

84. Magnusson, K., R. Simon, D. Sjolander, C.J. Sigurdson, P. Hammarstrom, and K.P. Nilsson, Multimodal fluorescence microscopy of prion strain specific PrP deposits stained by thiophene-based amyloid ligands. Prion, 2014. 8: p. 319-29.

85. Shirani, H., H. Appelqvist, M. Bäck, T. Klingstedt, N.J. Cairns, and K.P.R. Nilsson, Synthesis of Thiophene-Based Optical Ligands That Selectively Detect Tau Pathology in Alzheimer's Disease. Chemistry - A European Journal, 2017. 23: p. 17127-17135.

86. Jensen, L.E. and A.S. Whitehead, Regulation of serum amyloid A protein expression during the acute-phase response. Biochem J, 1998. 334 p. 489-503.

87. Steel, D.M. and A.S. Whitehead, The major acute phase reactants: C-reactive protein, serum amyloid $P$ component and serum amyloid A protein. Immunol Today, 1994. 15: p. 81-8.

88. Tosi, M.F., Innate immune responses to infection. Journal of Allergy and Clinical Immunology, 2005. 116: p. 241-249.

89. Turvey, S.E. and D.H. Broide, Innate immunity. Journal of Allergy and Clinical Immunology, 2010. 125: p. S24-S32.

90. Libby, P., Inflammatory mechanisms: the molecular basis of inflammation and disease. Nutr Rev, 2007. 65: p. S140-6. 
91. Chen, L., H. Deng, H. Cui, J. Fang, Z. Zuo, J. Deng, Y. Li, X. Wang, and L. Zhao, Inflammatory responses and inflammation-associated diseases in organs. Oncotarget, 2017. 9: p. 7204-7218.

92. Mogensen, T.H., Pathogen Recognition and Inflammatory Signaling in Innate Immune Defenses. Clinical Microbiology Reviews, 2009. 22: p. 240-273.

93. Lopez-Castejon, G. and D. Brough, Understanding the mechanism of IL-1beta secretion. Cytokine Growth Factor Rev, 2011. 22: p. 189-95.

94. Martinon, F., K. Burns, and J. Tschopp, The inflammasome: a molecular platform triggering activation of inflammatory caspases and processing of proIL-beta. Mol Cell, 2002. 10: p. 417-26.

95. Niemi, K., L. Teirila, J. Lappalainen, K. Rajamaki, M.H. Baumann, K. Oorni, H. Wolff, P.T. Kovanen, S. Matikainen, and K.K. Eklund, Serum amyloid A activates the NLRP3 inflammasome via $P 2 X 7$ receptor and a cathepsin B-sensitive pathway. J Immunol, 2011. 186: p. 6119-28.

96. Guma, M., L. Ronacher, R. Liu-Bryan, S. Takai, M. Karin, and M. Corr, Caspase 1independent activation of interleukin-1 $\hat{I}^{2}$ in neutrophil-predominant inflammation. Arthritis \& Rheumatism, 2009. 60: p. 3642-3650.

97. Kono, H., G.M. Orlowski, Z. Patel, and K.L. Rock, The IL-1-Dependent Sterile Inflammatory Response Has a Substantial Caspase-1-Independent Component That Requires Cathepsin C. The Journal of Immunology, 2012. 189: p. 3734-3740.

98. Kisilevsky, R. and P.N. Manley, Acute-phase serum amyloid A: perspectives on its physiological and pathological roles. Amyloid, 2012. 19: p. 5-14.

99. Sack, G.H., Serum amyloid A - a review. Molecular Medicine, 2018. 24: p. 46.

100. Westermark, G.T., K. Sletten, A. Grubb, and P. Westermark, AA-amyloidosis. Tissue component-specific association of various protein AA subspecies and evidence of a fourth SAA gene product. Am J Pathol, 1990. 137: p. 377-83.

101. Uhlar, C.M. and A.S. Whitehead, Serum amyloid A, the major vertebrate acute-phase reactant. Eur J Biochem, 1999. 265: p. 501-23.

102. Lu, J., Y. Yu, I. Zhu, Y. Cheng, and P.D. Sun, Structural mechanism of serum amyloid Amediated inflammatory amyloidosis. Proc Natl Acad Sci U S A, 2014. 111: p. 5189-94.

103. Sun, L. and R.D. Ye, Serum amyloid A1: Structure, function and gene polymorphism. Gene, 2016. 583: p. 48-57. 
104. Frame, N.M. and O. Gursky, Structure of serum amyloid A suggests a mechanism for selective lipoprotein binding and functions: SAA as a hub in macromolecular interaction networks. FEBS Lett, 2016. 590: p. 866-79.

105. Westermark, P., The heterogeneity of protein AA in secondary (reactive)systemic amyloidosis. Biochim Biophys Acta, 1982. 701: p. 19-23.

106. Sletten, K. and G. Husby, The complete amino-acid sequence of non-immunoglobulin amyloid fibril protein AS in rheumatoid arthritis. Eur J Biochem, 1974. 41: p. 117-25.

107. Yamada, T., J.J. Liepnieks, B. Kluve-Beckerman, and M.D. Benson, Cathepsin B generates the most common form of amyloid $A$ (76 residues) as a degradation product from serum amyloid A. Scand J Immunol, 1995. 41: p. 94-7.

108. Westermark, P., K. Sletten, and M. Eriksson, Morphologic and chemical variation of the kidney lesions in amyloidosis secondary to rheumatoid arthritis. Lab Invest, 1979. 41: p. 427-31.

109. Röcken, C. and A. Shakespeare, Pathology, diagnosis and pathogenesis of AA amyloidosis. Virchows Archiv, 2002. 440: p. 111-122.

110. Westermark, P., Subcutaneous adipose tissue biopsy for amyloid protein studies. Methods Mol Biol, 2012. 849: p. 363-71.

111. Schonland, S.O., U. Hegenbart, T. Bochtler, A. Mangatter, M. Hansberg, A.D. Ho, P. Lohse, and C. Rocken, Immunohistochemistry in the classification of systemic forms of amyloidosis: a systematic investigation of 117 patients. Blood, 2012. 119: p. 488-93.

112. Okuda, Y., M. Ohnishi, K. Matoba, K. Jouyama, A. Yamada, N. Sawada, S. Mokuda, Y. Murata, and K. Takasugi, Comparison of the clinical utility of tocilizumab and anti-TNF therapy in AA amyloidosis complicating rheumatic diseases. Mod Rheumatol, 2014. 24 : p. 137-43.

113. Dember, L.M., P.N. Hawkins, B.P. Hazenberg, P.D. Gorevic, G. Merlini, I. Butrimiene, A. Livneh, O. Lesnyak, X. Puechal, H.J. Lachmann, L. Obici, R. Balshaw, D. Garceau, W. Hauck, M. Skinner, and A.A.A.T.G. Eprodisate for, Eprodisate for the treatment of renal disease in AA amyloidosis. N Engl J Med, 2007. 356: p. 2349-60.

114. Bodin, K., S. Ellmerich, M.C. Kahan, G.A. Tennent, A. Loesch, J.A. Gilbertson, W.L. Hutchinson, P.P. Mangione, J.R. Gallimore, D.J. Millar, S. Minogue, A.P. Dhillon, G.W. Taylor, A.R. Bradwell, A. Petrie, J.D. Gillmore, V. Bellotti, M. Botto, P.N. Hawkins, and M.B. Pepys, Antibodies to human serum amyloid $P$ component eliminate visceral amyloid deposits. Nature, 2010. 468: p. 93-7. 
115. Hoffman, J.S., L.H. Ericsson, N. Eriksen, K.A. Walsh, and E.P. Benditt, Murine tissue amyloid protein AA. NH2-terminal sequence identity with only one of two serum amyloid protein (ApoSAA) gene products. J Exp Med, 1984. 159: p. 641-6.

116. Ishihara, T., Experimental amyloidosis using silver nitrate--electron microscopic study on the relationship between silver granules, amyloid fibrils and reticuloendothelial system. Acta Pathol Jpn, 1973. 23: p. 439-64.

117. Sponarova, J., M. Nuvolone, C. Whicher, N. Frei, V. Kana, P. Schwarz, G.T. Westermark, and A. Aguzzi, Efficient amyloid A clearance in the absence of immunoglobulins and complement factors. Am J Pathol, 2013. 182: p. 1297-307.

118. McAdam, K.P., Murine model for human secondary amyloidosis: genetic variability of the acute-phase serum protein SAA response to endotoxins and casein. Journal of Experimental Medicine, 1976. 144: p. 1121-1127.

119. Buxbaum, J.N., Animal models of human amyloidoses: Are transgenic mice worth the time and trouble? FEBS Letters, 2009. 583: p. 2663-2673.

120. Woldemeskel, M., A Concise Review of Amyloidosis in Animals. Veterinary Medicine International, 2012. 2012: p. 1-11.

121. Skinner, M., T. Shirahama, M.D. Benson, and A.S. Cohen, Murine amyloid protein AA in casein-induced experimental amyloidosis. Lab Invest, 1977. 36: p. 420-7.

122. Westermark, P., K. Lundmark, and G.T. Westermark, Fibrils from Designed NonAmyloid-Related Synthetic Peptides Induce AA-Amyloidosis during Inflammation in an Animal Model. PLoS ONE, 2009. 4: p. e6041.

123. Gruys, E. and F.W.J.J. Snel, Animal models for reactive amyloidosis. Baillière's Clinical Rheumatology, 1994. 8: p. 599-611.

124. Takahashi, M., T. Yokota, H. Kawano, T. Gondo, T. Ishihara, and F. Uchino, Ultrastructural evidence for intracellular formation of amyloid fibrils in macrophages. Virchows Arch A Pathol Anat Histopathol, 1989. 415: p. 411-9.

125. Lundmark, K., G.T. Westermark, S. Nystrom, C.L. Murphy, A. Solomon, and P. Westermark, Transmissibility of systemic amyloidosis by a prion-like mechanism. Proc Natl Acad Sci U S A, 2002. 99: p. 6979-84.

126. Varga, J., M.S. Flinn, T. Shirahama, O.G. Rodgers, and A.S. Cohen, The induction of accelerated murine amyloid with human splenic extract. Probable role of amyloid enhancing factor. Virchows Arch B Cell Pathol Incl Mol Pathol, 1986. 51: p. 177-85. 
127. Lundmark, K., G.T. Westermark, A. Olsen, and P. Westermark, Protein fibrils in nature can enhance amyloid protein A amyloidosis in mice: Cross-seeding as a disease mechanism. Proceedings of the National Academy of Sciences, 2005. 102: p. 6098-6102.

128. Ganowiak, K., P. Hultman, U. Engstrom, A. Gustavsson, and P. Westermark, Fibrils from synthetic amyloid-related peptides enhance development of experimental AA-amyloidosis in mice. Biochem Biophys Res Commun, 1994. 199: p. 306-12.

129. Mambule, C., Y. Ando, I. Anan, G. Holmgren, O. Sandgren, T. Stigbrandt, K. Tashima, and O.B. Suhr, Enhancement of AA-amyloid formation in mice by transthyretin amyloid fragments and polyethylene glycol. Biochim Biophys Acta, 2000. 1474: p. 331-6.

130. Jo, E., J. McLaurin, C.M. Yip, P. St George-Hyslop, and P.E. Fraser, alpha-Synuclein membrane interactions and lipid specificity. J Biol Chem, 2000. 275: p. 34328-34.

131. Vetrivel, K.S. and G. Thinakaran, Membrane rafts in Alzheimer's disease beta-amyloid production. Biochim Biophys Acta, 2010. 1801: p. 860-7.

132. Mebius, R.E. and G. Kraal, Structure and function of the spleen. Nat Rev Immunol, 2005. 5: p. 606-16.

133. Xu, L., M. Kwak, W. Zhang, P.C. Lee, and J.O. Jin, Time-dependent effect of E. coli LPS in spleen DC activation in vivo: Alteration of numbers, expression of co-stimulatory molecules, production of pro-inflammatory cytokines, and presentation of antigens. Mol Immunol, 2017. 85: p. 205-213.

134. Wiig, H., Pathophysiology of tissue fluid accumulation in inflammation. J Physiol, 2011. 589: p. 2945-53.

135. Semaeva, E., O. Tenstad, J. Skavland, M. Enger, P.O. Iversen, B.T. Gjertsen, and H. Wiig, Access to the spleen microenvironment through lymph shows local cytokine production, increased cell flux, and altered signaling of immune cells during lipopolysaccharideinduced acute inflammation. J Immunol, 2010. 184: p. 4547-56.

136. Borges da Silva, H., R. Fonseca, R.M. Pereira, A.d.A. Cassado, J.M. Álvarez, and M.R. D'Império Lima, Splenic Macrophage Subsets and Their Function during Blood-Borne Infections. Frontiers in Immunology, 2015. 6: p. 480.

137. A-Gonzalez, N. and A. Castrillo, Origin and specialization of splenic macrophages. Cellular Immunology, 2018. 330: p. 151-158.

138. Fujiyama, S., C. Nakahashi-Oda, F. Abe, Y. Wang, K. Sato, and A. Shibuya, Identification and isolation of splenic tissue-resident macrophage sub-populations by flow cytometry. International Immunology, 2019. 31: p. 51-56. 
139. Bratosin, D., J. Mazurier, J.P. Tissier, J. Estaquier, J.J. Huart, J.C. Ameisen, D. Aminoff, and J. Montreuil, Cellular and molecular mechanisms of senescent erythrocyte phagocytosis by macrophages. A review. Biochimie, 1998. 80: p. 173-95.

140. Kohyama, M., W. Ise, B.T. Edelson, P.R. Wilker, K. Hildner, C. Mejia, W.A. Frazier, T.L. Murphy, and K.M. Murphy, Role for Spi-C in the development of red pulp macrophages and splenic iron homeostasis. Nature, 2009. 457: p. 318-21.

141. Suenaga, G., T. Ikeda, Y. Komohara, K. Takamatsu, T. Kakuma, M. Tasaki, Y. Misumi, M. Ueda, T. Ito, S. Senju, and Y. Ando, Involvement of Macrophages in the Pathogenesis of Familial Amyloid Polyneuropathy and Efficacy of Human iPS Cell-Derived Macrophages in Its Treatment. PLoS One, 2016. 11: p. e0163944.

142. Westwell-Roper, C.Y., J.A. Ehses, and C.B. Verchere, Resident Macrophages Mediate Islet Amyloid Polypeptide-Induced Islet IL-1 $\beta$ Production and $\beta$-Cell Dysfunction. Diabetes, 2014. 63: p. 1698-1711.

143. Nystrom, S.N. and G.T. Westermark, AA-Amyloid is cleared by endogenous immunological mechanisms. Amyloid, 2012. 19: p. 138-45.

144. Rocken, C., B. Stix, D. Bromme, S. Ansorge, A. Roessner, and F. Buhling, A putative role for cathepsin $K$ in degradation of $A A$ and $A L$ amyloidosis. Am J Pathol, 2001. 158: p. 1029-38.

145. Chronopoulos, S., D.W. Laird, and Z. Ali-Khan, Immunolocalization of serum amyloid A and AA amyloid in lysosomes in murine monocytoid cells: confocal and immunogold electron microscopic studies. J Pathol, 1994. 173: p. 361-9.

146. Skogen, B., L. Thorsteinsson, and J.B. Natvig, Degradation of protein SAA to an AA-like fragment by enzymes of monocytic origin. Scand J Immunol, 1980. 11: p. 533-40.

147. Shirahama, T. and A.S. Cohen, Redistribution of amyloid deposits. Am J Pathol, 1980. 99: p. 539-50.

148. Hawkins, P.N. and M.B. Pepys, A primed state exists in vivo following histological regression of amyloidosis. Clin Exp Immunol, 1990. 81: p. 325-8.

149. Wright, J.R., A.I. Ozdemir, M. Matsuzaki, P. Binette, and E. Calkins, Amylod resorption: possible role of multinucleated giant cells. The apparent failure of penicillamine treatment. Johns Hopkins Med J, 1972. 130: p. 278-88.

150. Glojnaric, I., S. Cuzic, V. Erakovic-Haber, and M.J. Parnham, The serum amyloid A response to sterile silver nitrate in mice and its inhibition by dexamethasone and macrolide antibiotics. Int Immunopharmacol, 2007. 7: p. 1544-51. 
151. Clement, C.G. and L.D. Truong, An evaluation of Congo red fluorescence for the diagnosis of amyloidosis. Hum Pathol, 2014. 45: p. 1766-72.

152. Nyström, S., M. Bäck, K.P.R. Nilsson, and P. Hammarström, Imaging Amyloid Tissues Stained with Luminescent Conjugated Oligothiophenes by Hyperspectral Confocal Microscopy and Fluorescence Lifetime Imaging. Journal of Visualized Experiments, 2017. 20: p. 56279.

153. Ellingsen, P.G., S. Nystrom, N.K. Reitan, and M. Lindgren, Spectral correlation analysis of amyloid beta plaque inhomogeneity from double staining experiments. J Biomed Opt, 2013. 18: p. 101313.

154. Akbarzadeh, A., R. Rezaei-Sadabady, S. Davaran, S.W. Joo, N. Zarghami, Y. Hanifehpour, M. Samiei, M. Kouhi, and K. Nejati-Koshki, Liposome: classification, preparation, and applications. Nanoscale Res Lett, 2013. 8: p. 102.

155. Ishida, T., H. Harashima, and H. Kiwada, Liposome clearance. Biosci Rep, 2002. 22: p. 197-224.

156. Hernandez-Caselles, T., J. Villalain, and J.C. Gomez-Fernandez, Influence of liposome charge and composition on their interaction with human blood serum proteins. Mol Cell Biochem, 1993. 120: p. 119-26.

157. Bozzuto, G. and A. Molinari, Liposomes as nanomedical devices. International Journal of Nanomedicine, 2015. 10: p. 975-999.

158. Buiting, A.M., F. Zhou, J.A. Bakker, N. van Rooijen, and L. Huang, Biodistribution of clodronate and liposomes used in the liposome mediated macrophage 'suicide' approach. J Immunol Methods, 1996. 192: p. 55-62.

159. Rogers, M.J., J.C. Crockett, F.P. Coxon, and J. Monkkonen, Biochemical and molecular mechanisms of action of bisphosphonates. Bone, 2011. 49: p. 34-41.

160. Plosker, G.L. and K.L. Goa, Clodronate. A review of its pharmacological properties and therapeutic efficacy in resorptive bone disease. Drugs, 1994. 47: p. 945-82.

161. van Rooijen, N., Liposome-mediated elimination of macrophages. Res Immunol, 1992. 143: p. 215-9.

162. Lehenkari, P.P., Further Insight into Mechanism of Action of Clodronate: Inhibition of Mitochondrial ADP/ATP Translocase by a Nonhydrolyzable, Adenine-Containing Metabolite. Molecular Pharmacology, 2002. 61: p. 1255-1262.

163. van Rooijen, N. and E. Hendrikx, Liposomes for specific depletion of macrophages from organs and tissues. Methods Mol Biol, 2010. 605: p. 189-203. 
164. Donaldson, J.G., Immunofluorescence Staining. Curr Protoc Cell Biol, 2015. 69: p. 1-7.

165. Ralph, P. and I. Nakoinz, Phagocytosis and cytolysis by a macrophage tumour and its cloned cell line. Nature, 1975. 257: p. 393-4.

166. Kant, A.M., P. De, X. Peng, T. Yi, D.J. Rawlings, J.S. Kim, and D.L. Durden, SHP-1 regulates Fcgamma receptor-mediated phagocytosis and the activation of $R A C$. Blood, 2002. 100: p. 1852-9.

167. Lam, J., M. Herant, M. Dembo, and V. Heinrich, Baseline Mechanical Characterization of J774 Macrophages. Biophysical Journal, 2009. 96: p. 248-254.

168. Weidmann, E., J. Brieger, B. Jahn, D. Hoelzer, L. Bergmann, and P.S. Mitrou, Lactate dehydrogenase-release assay: a reliable, nonradioactive technique for analysis of cytotoxic lymphocyte-mediated lytic activity against blasts from acute myelocytic leukemia. Ann Hematol, 1995. 70: p. 153-8.

169. Chan, F.K.-M., K. Moriwaki, and M.J. De Rosa, Detection of Necrosis by Release of Lactate Dehydrogenase Activity. 2013. 979: p. 65-70.

170. Lema, C., A. Varela-Ramirez, and R.J. Aguilera, Differential nuclear staining assay for high-throughput screening to identify cytotoxic compounds. Curr Cell Biochem, 2011. 1: p. 1-14.

171. Roseman, M. and W.P. Jencks, Interactions of urea and other polar compounds in water. Journal of the American Chemical Society, 1975. 97: p. 631-640.

172. Rossky, P.J., Protein denaturation by urea: Slash and bond. Proceedings of the National Academy of Sciences, 2008. 105: p. 16825-16826.

173. Sackett, D.L. and J. Wolff, Nile red as a polarity-sensitive fluorescent probe of hydrophobic protein surfaces. Anal Biochem, 1987. 167: p. 228-34.

174. Mishra, R., D. Sjölander, and P. Hammarström, Spectroscopic characterization of diverse amyloid fibrils in vitro by the fluorescent dye Nile red. Molecular BioSystems, 2011. 7: p. 1232.

175. Bergstrom, J., A. Gustavsson, U. Hellman, K. Sletten, C.L. Murphy, D.T. Weiss, A. Solomon, B.O. Olofsson, and P. Westermark, Amyloid deposits in transthyretin-derived amyloidosis: cleaved transthyretin is associated with distinct amyloid morphology. $\mathrm{J}$ Pathol, 2005. 206: p. 224-32.

176. Solomon, A., D.T. Weiss, M. Schell, R. Hrncic, C.L. Murphy, J. Wall, M.D. McGavin, H.J. Pan, G.W. Kabalka, and M.J. Paulus, Transgenic Mouse Model of AA Amyloidosis. The American Journal of Pathology, 1999. 154: p. 1267-1272. 
177. Solomon, A., T. Richey, C.L. Murphy, D.T. Weiss, J.S. Wall, G.T. Westermark, and P. Westermark, Amyloidogenic potential of foie gras. Proceedings of the National Academy of Sciences, 2007. 104: p. 10998-11001.

178. Simons, J.P., R. Al-Shawi, S. Ellmerich, I. Speck, S. Aslam, W.L. Hutchinson, P.P. Mangione, P. Disterer, J.A. Gilbertson, T. Hunt, D.J. Millar, S. Minogue, K. Bodin, M.B. Pepys, and P.N. Hawkins, Pathogenetic mechanisms of amyloid A amyloidosis. Proc Natl Acad Sci U S A, 2013. 110: p. 16115-20.

179. Muhammad, N., T. Murakami, Y. Inoshima, and N. Ishiguro, Long-term kinetics of AA amyloidosis and effects of inflammatory restimulation after disappearance of amyloid depositions in mice. Clin Exp Immunol, 2015. 181: p. 133-41.

180. Gillmore, J.D., L.B. Lovat, M.R. Persey, M.B. Pepys, and P.N. Hawkins, Amyloid load and clinical outcome in AA amyloidosis in relation to circulating concentration of serum amyloid A protein. Lancet, 2001. 358: p. 24-9.

181. Lachmann, H.J., H.J. Goodman, J.A. Gilbertson, J.R. Gallimore, C.A. Sabin, J.D. Gillmore, and P.N. Hawkins, Natural history and outcome in systemic AA amyloidosis. N Engl J Med, 2007. 356: p. 2361-71.

182. Furlaneto, C.J. and A. Campa, A Novel Function of Serum Amyloid A: A Potent Stimulus for the Release of Tumor Necrosis Factor- $\alpha$, Interleukin-1 $\beta$, and Interleukin- 8 by Human Blood Neutrophil. Biochemical and Biophysical Research Communications, 2000. 268: p. 405-408.

183. Patel, H., R. Fellowes, S. Coade, and P. Woo, Human serum amyloid A has cytokine-like properties. Scand J Immunol, 1998. 48: p. 410-8.

184. Masters, S.L., A. Dunne, S.L. Subramanian, R.L. Hull, G.M. Tannahill, F.A. Sharp, C. Becker, L. Franchi, E. Yoshihara, Z. Chen, N. Mullooly, L.A. Mielke, J. Harris, R.C. Coll, K.H. Mills, K.H. Mok, P. Newsholme, G. Nunez, J. Yodoi, S.E. Kahn, E.C. Lavelle, and L.A. O'Neill, Activation of the NLRP3 inflammasome by islet amyloid polypeptide provides a mechanism for enhanced IL-1beta in type 2 diabetes. Nat Immunol, 2010. 11: p. 897-904.

185. Lavie, G., D. Zucker-Franklin, and E.C. Franklin, Degradation of serum amyloid A protein by surface-associated enzymes of human blood monocytes. J Exp Med, 1978. 148: p. 1020-31.

186. Rocken, C., M. Fandrich, B. Stix, A. Tannert, P. Hortschansky, T. Reinheckel, P. Saftig, T. Kahne, R. Menard, J.B. Ancsin, and F. Buhling, Cathepsin protease activity modulates amyloid load in extracerebral amyloidosis. J Pathol, 2006. 210: p. 478-87.

187. Yamada, T., B. Kluve-Beckerman, J.J. Liepnieks, and M.D. Benson, In vitro degradation of serum amyloid $A$ by cathepsin $D$ and other acid proteases: possible protection against amyloid fibril formation. Scand J Immunol, 1995. 41: p. 570-4. 
188. Claus, S., K. Meinhardt, T. Aumuller, I. Puscalau-Girtu, J. Linder, C. Haupt, P. Walther, T. Syrovets, T. Simmet, and M. Fandrich, Cellular mechanism of fibril formation from serum amyloid A1 protein. EMBO Rep, 2017. 18: p. 1352-1366.

189. Kluve-Beckerman, B., J.J. Manaloor, and J.J. Liepnieks, A pulse-chase study tracking the conversion of macrophage-endocytosed serum amyloid A into extracellular amyloid. Arthritis \& Rheumatism, 2002. 46: p. 1905-1913.

190. Chorro, L., A. Sarde, M. Li, K.J. Woollard, P. Chambon, B. Malissen, A. Kissenpfennig, J.-B. Barbaroux, R. Groves, and F. Geissmann, Langerhans cell (LC) proliferation mediates neonatal development, homeostasis, and inflammation-associated expansion of the epidermal LC network. The Journal of Experimental Medicine, 2009. 206: p. 30893100 .

191. Davies, L.C., M. Rosas, P.J. Smith, D.J. Fraser, S.A. Jones, and P.R. Taylor, A quantifiable proliferative burst of tissue macrophages restores homeostatic macrophage populations after acute inflammation. European Journal of Immunology, 2011. 41: p. 2155-2164.

192. Yamada, M., M. Naito, and K. Takahashi, Kupffer cell proliferation and glucan-induced granuloma formation in mice depleted of blood monocytes by strontium-89. J Leukoc Biol, 1990. 47: p. 195-205.

193. Jenkins, S.J., D. Ruckerl, P.C. Cook, L.H. Jones, F.D. Finkelman, N. van Rooijen, A.S. MacDonald, and J.E. Allen, Local Macrophage Proliferation, Rather than Recruitment from the Blood, Is a Signature of TH2 Inflammation. Science, 2011. 332: p. 1284-1288.

194. Backer, R., T. Schwandt, M. Greuter, M. Oosting, F. Jungerkes, T. Tuting, L. Boon, T. O'Toole, G. Kraal, A. Limmer, and J.M.M. den Haan, Effective collaboration between marginal metallophilic macrophages and CD8+ dendritic cells in the generation of cytotoxic T cells. Proceedings of the National Academy of Sciences, 2009. 107: p. 216221.

195. Nikbakht, N., S. Shen, and T. Manser, Cutting Edge: Macrophages Are Required for Localization of Antigen-Activated B Cells to the Follicular Perimeter and the Subsequent Germinal Center Response. The Journal of Immunology, 2013. 190: p. 4923-4927.

196. Kennel, S.J., S. Macy, C. Wooliver, Y. Huang, T. Richey, E. Heidel, and J.S. Wall, Phagocyte depletion inhibits AA amyloid accumulation in AEF-induced huIL-6 transgenic mice. Amyloid, 2014. 21: p. 45-53.

197. Cremades, N., Samuel I.A. Cohen, E. Deas, Andrey Y. Abramov, Allen Y. Chen, A. Orte, M. Sandal, Richard W. Clarke, P. Dunne, Francesco A. Aprile, Carlos W. Bertoncini, Nicholas W. Wood, Tuomas P.J. Knowles, Christopher M. Dobson, and D. Klenerman, Direct Observation of the Interconversion of Normal and Toxic Forms of $\alpha$-Synuclein. Cell, 2012. 149: p. 1048-1059. 
198. Howlett, D.R., K.H. Jennings, D.C. Lee, M.S. Clark, F. Brown, R. Wetzel, S.J. Wood, P. Camilleri, and G.W. Roberts, Aggregation state and neurotoxic properties of Alzheimer beta-amyloid peptide. Neurodegeneration, 1995. 4: p. 23-32.

199. Knight, J.D. and A.D. Miranker, Phospholipid catalysis of diabetic amyloid assembly. J Mol Biol, 2004. 341: p. 1175-87.

200. Ehehalt, R., P. Keller, C. Haass, C. Thiele, and K. Simons, Amyloidogenic processing of the Alzheimer beta-amyloid precursor protein depends on lipid rafts. J Cell Biol, 2003. 160: p. 113-23.

201. Price, K.A., P.J. Crouch, P.S. Donnelly, C.L. Masters, A.R. White, and C.C. Curtain, Membrane-targeted strategies for modulating APP and Abeta-mediated toxicity. J Cell Mol Med, 2009. 13: p. 249-61.

202. Jayaraman, S., C. Haupt, and O. Gursky, Thermal transitions in serum amyloid $A$ in solution and on the lipid: implications for structure and stability of acute-phase HDL. Journal of Lipid Research, 2015. 56: p. 1531-1542.

203. Fezoui, Y. and D.B. Teplow, Kinetic studies of amyloid beta-protein fibril assembly. Differential effects of alpha-helix stabilization. J Biol Chem, 2002. 277: p. 36948-54.

204. Uversky, V.N., Protein Misfolding in Lipid-Mimetic Environments. 2015. 855: p. 33-66.

205. Nixon, R.A., A.M. Cataldo, and P.M. Mathews, The endosomal-lysosomal system of neurons in Alzheimer's disease pathogenesis: a review. Neurochem Res, 2000. 25: p. 1161-72.

206. Colon, W. and J.W. Kelly, Partial denaturation of transthyretin is sufficient for amyloid fibril formation in vitro. Biochemistry, 1992. 31: p. 8654-60.

207. Jayaraman, S., D.L. Gantz, C. Haupt, and O. Gursky, Serum amyloid A forms stable oligomers that disrupt vesicles at lysosomal $\mathrm{pH}$ and contribute to the pathogenesis of reactive amyloidosis. Proc Natl Acad Sci U S A, 2017. 114: p. E6507-E6515.

208. Maarouf, C.L., I.D. Daugs, S. Spina, R. Vidal, T.A. Kokjohn, R.L. Patton, W.M. Kalback, D.C. Luehrs, D.G. Walker, E.M. Castaño, T.G. Beach, B. Ghetti, and A.E. Roher, Histopathological and molecular heterogeneity among individuals with dementia associated with Presenilin mutations. Molecular Neurodegeneration, 2008. 3: p. 20.

209. Westermark, G.T., K. Sletten, and P. Westermark, Massive vascular AA-amyloidosis: a histologically and biochemically distinctive subtype of reactive systemic amyloidosis. Scand J Immunol, 1989. 30: p. 605-13.

210. Meyer-Luehmann, M., J. Coomaraswamy, T. Bolmont, S. Kaeser, C. Schaefer, E. Kilger, A. Neuenschwander, D. Abramowski, P. Frey, A.L. Jaton, J.M. Vigouret, P. Paganetti, 
D.M. Walsh, P.M. Mathews, J. Ghiso, M. Staufenbiel, L.C. Walker, and M. Jucker, Exogenous induction of cerebral beta-amyloidogenesis is governed by agent and host. Science, 2006. 313: p. 1781-4.

211. Peretz, D., R.A. Williamson, G. Legname, Y. Matsunaga, J. Vergara, D.R. Burton, S.J. DeArmond, S.B. Prusiner, and M.R. Scott, A change in the conformation of prions accompanies the emergence of a new prion strain. Neuron, 2002. 34: p. 921-32.

212. Axelrad, M.A., R. Kisilevsky, J. Willmer, S.J. Chen, and M. Skinner, Further characterization of amyloid-enhancing factor. Lab Invest, 1982. 47: p. 139-46.

213. Johan, K., G. Westermark, U. Engstrom, A. Gustavsson, P. Hultman, and P. Westermark, Acceleration of amyloid protein A amyloidosis by amyloid-like synthetic fibrils. Proc Natl Acad Sci U S A, 1998. 95: p. 2558-63.

214. Murakami, T., Y. Inoshima, and N. Ishiguro, Systemic AA amyloidosis as a prion-like disorder. Virus Research, 2015. 207: p. 76-81.

215. Psonka-Antonczyk, K.M., P. Hammarström, L.B.G. Johansson, M. Lindgren, B.T. Stokke, K.P.R. Nilsson, and S. Nyström, Nanoscale Structure and Spectroscopic Probing of AB1-40 Fibril Bundle Formation. Frontiers in Chemistry, 2016. 4: p. 44.

216. Ma, J., H. Komatsu, Y.S. Kim, L. Liu, R.M. Hochstrasser, and P.H. Axelsen, Intrinsic structural heterogeneity and long-term maturation of amyloid beta peptide fibrils. ACS Chem Neurosci, 2013. 4: p. 1236-43.

217. Liberta, F., S. Loerch, M. Rennegarbe, A. Schierhorn, P. Westermark, G.T. Westermark, B.P.C. Hazenberg, N. Grigorieff, M. Fändrich, and M. Schmidt, Cryo-EM fibril structures from systemic AA amyloidosis reveal the species complementarity of pathological amyloids. Nature Communications, 2019. 10: p. 1104.

218. Jonson, M., S. Nystrom, A. Sandberg, M. Carlback, W. Michno, J. Hanrieder, A. Starkenberg, K.P.R. Nilsson, S. Thor, and P. Hammarstrom, Aggregated Abetal-42 Is Selectively Toxic for Neurons, Whereas Glial Cells Produce Mature Fibrils with Low Toxicity in Drosophila. Cell Chem Biol, 2018. 25: p. 595-610 e5. 


\section{Papers}

The papers associated with this thesis have been removed for copyright reasons. For more details about these see:

http://urn.kb.se/resolve?urn=urn:nbn:se:liu:diva-159658 
